Universidad Autónoma Metropolitana unidad Iztapalapa División de Ciencias Biológicas y de la Salud

Casa abierta al tiempo

\title{
MAESTRÍA EN BIOLOGÍA EXPERIMENTAL
}

Estudio de Cucurbita ficifolia Bouché e Ibervillea sonorae Greene como secretagogos de insulina en células RINm5F

\section{T E S I S}

QUE PARA OBTENER EL GRADO DE MAESTRA EN BIOLOGÍA EXPERIMENTAL

P R E S E N T A:

\section{B.E. MARÍA ELIZABETH MIRANDA PÉREZ}

\author{
Directores: \\ Dr. Francisco Javier Alarcón Aguilar \\ Dra. Clara Ortega Camarillo \\ Asesor:
}

Dra. María del Carmen Escobar Villanueva

Diciembre del 2012 
"EI Programa de Maestría en Biología Experimental de la Universidad Autónoma Metropolitana pertenece al Programa Nacional de Posgrados de Calidad (PNPC) del CONACYT, registro 001481, en el Nivel Consolidado, y cuenta con apoyo del mismo Consejo, clave DAFCYT-2003IMPTNNN0020".

Número de registro de la beca otorgada por CONACYT y CVU del becario 248826 y 372741

Se agradece el apoyo brindado por el Consejo Mexiquense de Ciencia y Tecnología, COMECYT con número de folio 12BTM0111

Se agradece el apoyo brindado por PROMEP-SEP con número de folio P/CA15-2006-35-53 
El jurado designado por la Comisión Académica del Posgrado en Biología Experimental de la División de Ciencias Biológicas y de la Salud de la Universidad Autónoma Metropolitana aprobó la Tesis titulada: "Estudio de Cucurbita ficifolia Bouché e Ibervillea sonorae Greene como secretagogos de insulina en células RINm5F", que presentó

\section{María Elizabeth Miranda Pérez}

El día 5 de Diciembre del año 2012

\section{Sinodales}

\section{Presidente}

Julio César Almanza Pérez

Profesor-Investigador "C".

Universidad Autónoma Metropolitana.

D.C.B.S. Depto. Ciencias de la Salud.

\section{Secretario}

María Elena Larrieta Carrasco.

Investigador en Ciencias Médicas "C".

Instituto Nacional de Ciencias Médicas

y Nutrición "Salvador Zubirán".

\section{Vocal 1}

Fausto Sánchez Muñoz.

Investigador en Ciencias Médicas "C".

Instituto Nacional de Cardiología "Ignacio Chávez" Depto. Inmunología.

\section{Vocal 2}

María Del Carmen Escobar Villanueva.

Profesor investigador "C", Tiempo Completo.

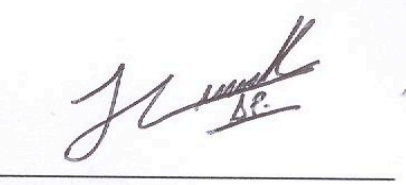

Universidad Autónoma Metropolitana.

D.C.B.S. Depto. Ciencias de la Salud.

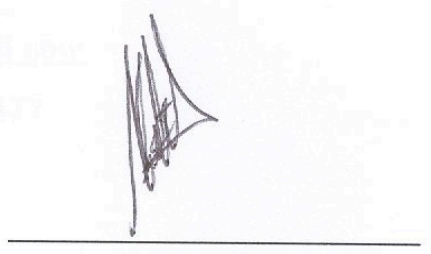


Comité tutoral

\author{
Codirector \\ Dr. Francisco Javier Alarcón Aguilar \\ Dpto. Ciencias de la Salud. D.C.B.S. \\ Universidad Autónoma Metropolitana - Iztapalapa. \\ Lab. de Farmacología (S-348) \\ aaasj2@prodigy.net.mx \\ Tel: 58046483

\section{Codirectora} \\ Dra. Clara Ortega Camarillo \\ UIM Bioquímica, Hospital de Especialidades, \\ CMN SXXI, IMSS \\ clara.ortegacamarillo@gmail.com
}

Tel: 56276900 ext. 21477

\author{
Asesora \\ Dra. María del Carmen Escobar Villanueva. \\ Depto. Ciencias de la Salud D.C.B.S. \\ Universidad Autónoma Metropolitana - Iztapalapa \\ Lab. de Farmacología (S-348) \\ mcev@xanum.uam.mx
}

Tel: 58046483 
DEDICATORIA

A mis Padres y hermanos, que siempre me brindan su apoyo incondicional

\section{AGRADECIMIENTOS}

A Dios, por permitir la culminación de esta meta.

A Jesús Miranda Acosta y Leticia Pérez Paredes (mis padres), por enseñarme a aprovechar las oportunidades que se me presentan, siempre alentarme en cada meta y por su apoyo incondicional. A mis hermanos Alberto y Luis, que creen en mí.

A los miembros del laboratorio de Farmacología; en especial al Dr. Francisco Javier Alarcón Aguilar, por despertar en mí un espíritu más crítico y analítico.

A la Dra. Clara Ortega Camarillo, por el apoyo que siempre he recibido de ella.

A la Dra. Ma. Del Carmen Escobar Villanueva y al Dr. Julio César Almanza Pérez, por su dedicación y tiempo brindado. Por guiarme en esta etapa de mi vida.

A mis amigos Gerardo, Erika, Wendy y Guillermo que siempre estuvieron ahí, que me escucharon, me brindaron su apoyo y me hicieron reír en momentos de estrés. 


\section{ABREVIATURAS}

ADA Asociación Americana de Diabetes

ADN Ácido desoxirribonucleico

ARNm Ácido ribonucleico mensajero

ATP Adenosin trifosfato

$\mathrm{Ca}^{2+} \quad$ Calcio

AMP cíclico Adenosín monofosfato-3',5'

Cdkal1 Por sus siglas en inglés: cyclin-dependent kinase 5 regulatory subunit associated protein 1-like 1

cDNA Cadena complementaria al Ácido desoxirribonucleíco

DAG Diacilglicerol

DGE Dirección General de Epidemiología

DM Diabetes mellitus

DPP4 Dipeptidil peptidasa 4

DQI D-quiro inositol

DT1 Diabetes tipo 1

DT2 Diabetes tipo 2

FMD Federación Mexicana de Diabetes

FOXA2 Forkhead box a2, formerly Hepatocyte nuclear factor 3beta

GAD65 Isoforma más pequeña de glutamato descarboxilasa

GAD65Ab Autoanticuerpos dirigidos a GAD65

GIP Polipéptido insulinotrófico dependiente de glucosa

GLP-1 Péptido semejante al glucagón 1

Glib Glibenclamida

GLUT-2 Transportador de glucosa 2

GRB2 Proteína 2 unida al receptor del factor de crecimiento 
HLA Human Leucocyte Antigen

HMGA1 Por sus siglas en ingles: Variants of high-mobility group A1

IDF Federación Internacional de Diabetes

InsP3R Receptor inositol 1,4,5-trifosfato

IP3 Inositol trifosfato

IRS1 Receptor de insulina 1

IRS2 Receptor de insulina 2

$\mathrm{K}^{+} \quad$ Potasio

$\mathrm{K}^{+}$ATP $\quad$ Canal de $\mathrm{K}^{+}$dependiente de ATP

Kir6.2 Subunidad formadora del canal de $\mathrm{K}^{+}{ }_{\text {ATP }}$

(LXR)- $\boldsymbol{\alpha}, \boldsymbol{\beta} \quad$ Receptores del hígado alfa y beta

MafA Factor de transcripción v-maf fibrosarcoma músculo-homólogo del oncogén $A$

MAP cinasas Proteínas activadas por mitógenos

MCT1 Proteína transportadora de monocarboxilatos

miRNA microRNA

MTT Bromuro de 3-(4,5-dimetiltiazol-2yl)-2,5-difenil tetrazolium

NeuroD1 Factor de diferenciación neurogénica 1

NR1H2 Nuclear receptor subfamily 1, group $\mathrm{H}$, member 2

NR1H3 Nuclear receptor subfamily 1, group $\mathrm{H}$, member 3

OMS Organización Mundial de la Salud

PBS Solución salina amortiguadora de fosfatos

PCR Reacción en cadena de la polimeras

Pdx-1 Factor de transcripción pancreático/duodenal homeobox-1

PI3K Fosfatidilinositol 3-cinasa

PKA Proteína cinasa A

PKC Proteína cinasa C 
PLC Fosfolipasa C

RE Retículo endoplásmico

RI Resistencia a la insulina

Ros Especies reactivas de oxígeno

SH2 De homología al dominio 2 de la proteína Src

SNARE Por sus siglas en ingles: soluble N-ethylmeleimide-sensitive factor attachment protein receptor

SUR1 Receptor de sulfonilurea 


\section{Resumen}

\section{Introducción}

La diabetes mellitus (DM) es un desorden metabólico de etiología múltiple. Se caracteriza por hiperglucemia crónica, con alteraciones del metabolismo de carbohidratos, grasas y proteínas, como resultado de defectos en la secreción y/o acción de la insulina. A medida que transcurren los años su control metabólico es cada vez más difícil, convirtiéndose en un importante problema de salud pública a nivel mundial. La Federación Internacional de Diabetes (IDF por sus siglas en inglés) estimó en el 2010 que México ocupó la décima posición en el mundo con 6.8 millones de personas que padecen DM. La morbilidad asociada con diabetes, surge de las complicaciones microvasculares y macrovasculares. A pesar del amplio uso de medicamentos para esta enfermedad, más del $64 \%$ de la población mundial también recurre a la medicina tradicional. En México, dos especies de la familia Cucurbitaceae: Cucurbita ficifolia Bouché (C. ficifolia) e Ibervilliea sonorae Greene ( $I$. sonorae), son estudiadas debido a sus efectos hipoglucémicos. Estudios en ratones sanos y diabéticos, y pacientes con diabetes tipo 2 (DT2) que recibieron un extracto acuoso de C. ficifolia, mostraron una disminución significativa de los niveles de glucosa en sangre. En otro estudio, se midió la capacidad de este extracto para bloquear los canales de potasio dependiente de ATP $\left(\mathrm{K}^{+}{ }_{\text {ATP }}\right)$, en aorta torácica de rata. Con este estudio, se estableció si el efecto hipoglucémico del extracto acuoso de C. ficifolia podría estar asociado con la secreción de insulina, de manera similar a las sulfonilureas. El extracto acuoso de C. ficifolia no bloqueó los canales de $\mathrm{K}^{+}{ }_{\text {ATP, }}$ en aorta de rata torácica. Sin embargo, otro estudio en ratones diabéticos que recibieron el extracto acuoso de C. ficifolia, mostró mayor secreción de insulina a las 2 horas de la medición. Dando indicios 
de la secreción de insulina, por la administración del extracto acuoso de $C$. ficifolia. Desde el punto de vista fitoquímico, se propuso al D-quiro inositol (DQI) como la molécula responsable del efecto hipoglucémico del fruto de $C$. ficifolia. En otros estudios, el decremento de glucosa en sangre de ratas con diabetes experimental, se le atribuyó al DQI aislado de C. ficifolia.

Por otro lado, se ha demostrado también que un extracto acuoso de $I$. sonorae disminuye los niveles de glucosa en sangre de ratones sanos y con diabetes experimental. En otro estudio, se logró demostrar que bloquea los canales $\mathrm{K}^{+}$ATP en aorta torácica de rata, por lo que se ha sugerido que su mecanismo de acción hipoglucemiante podría estar asociado con la secreción de insulina, de manera similar a las sulfonilureas. Desde el punto de vista fitoquímico, se han propuesto a varios monoglicéridos y ácidos grasos como los responsables del efecto hipoglucémico en un extracto diclorometánico. En cuanto al extracto acuso, se le atribuye el efecto a las cucurbitacinas (terpenoides oxigenados tetracíclicos). Así, estas plantas representan una alternativa útil para el control de la DT2 al alcance de la mayoría de la población. No obstante, aún falta profundizar en el conocimiento de su efecto hipoglucémico. La cuantificación en la expresión del gen de insulina, en células tratadas con estos extractos, no se ha investigado aún. El objetivo de esta investigación es establecer la influencia de estos extractos sobre la producción y secreción de insulina en un cultivo de células secretoras de insulina (RINm5F). 


\section{Metodología}

La línea celular RINm5F (proveniente de insulinoma de rata), fue tratada 24 horas con el extracto acuoso de C. ficifolia $(0.25 \mu \mathrm{M})$ y con DQI $(0.25 \mu \mathrm{M})$. De manera independiente se probó el extracto de $\mathrm{I}$. sonorae $(0.25 \mu \mathrm{g} / \mathrm{mL})$. Se extrajo el ARN total de las células tratadas y se determinó la expresión de insulina y de Kir6.2 mediante PCR en tiempo real. Adicionalmente se cuantificó la concentración de insulina (mediante la técnica de ELISA) y $\mathrm{Ca}^{2+}$ (mediante un método espectrofotométrico).

\section{Resultados}

C. ficifolia y DQI incrementaron la expresión del ARNm de insulina 6 y 4 veces, respectivamente $(p \leq 0.0001)$ y Kir6.2 aumentó 150 veces más $(p \leq 0.0001)$, tanto con C. ficifolia y con DQI. La concentración intracelular de $\mathrm{Ca}^{2+}$ aumentó $160 \%$ ( $p \leq 0.0056)$. La secreción de insulina aumentó 11\%, $(p \leq 0.007)$. Por otro lado, $I$. sonorae redujo la expresión del gen de insulina $20 \%$ ( $p \leq 0.0001)$, la expresión de Kir6.2 no mostró cambios significativos. La concentración del $\mathrm{Ca}^{2+}$ intracelular aumentó 80\%, $(p \leq 0.001)$. La secreción de insulina aumentó 35\% ( $p \leq 0.0032)$.

\section{Conclusiones}

Se puede concluir que parte del efecto hipoglucémico del extracto acuoso de $C$. ficifolia involucra el aumento de la expresión de insulina y Kir6.2, secreción de insulina y aumento de $\mathrm{Ca}^{2+}$. Por su parte, el extracto acuoso de $\mathrm{I}$. sonorae disminuye la expresión de insulina, sin cambios en Kir6.2. Sin embargo, incrementa la concentración de $\mathrm{Ca}^{2+}$ intracelular, con el aumento de la secreción de insulina. 


\section{Summary}

\section{Introduction}

Diabetes mellitus (DM) is a metabolic disorder of multiple etiologies. It is characterized by chronic hyperglycaemia with disturbances of carbohydrate, fat and protein, resulting from defects in insulin secretion and/or insulin action. As the years pass metabolic control is increasingly difficult, becoming a major public health problem worldwide. The International Diabetes Federation (IDF for its acronym in English) estimated in 2010 that Mexico ranked tenth in the world with 6.8 million people with DM. The morbidity associated with diabetes, arises from microvascular and macrovascular complications. Despite the widespread use of drugs for this disease, more than $64 \%$ of the world population also uses traditional medicine. In Mexico, two species of the family Cucurbitaceae, Cucurbita ficifolia Bouché (C. ficifolia) and Ibervilliea sonorae Greene (I. sonorae) are studied because of its hypoglycemic effects. Studies in healthy and diabetic mice and patients with type 2 diabetes (T2D) who received an aqueous extract of $C$. ficifolia showed a significant decrease in blood glucose levels. In another study, we measured the ability of the extract channels to block ATP-dependent potassium $\left(\mathrm{K}^{+}{ }_{\mathrm{ATP}}\right)$, in the rat thoracic aorta. With this study, we tested if the hypoglycemic effect of the aqueous extract of $C$. ficifolia could be associated with the secretion of insulin, similar to sulfonylureas. The aqueous extract of $C$. ficifolia not blocked the $\mathrm{K}_{\text {ATP }}^{+}$channels in rat thoracic aorta. However, another study in diabetic mice that received the aqueous extract of $C$. ficifolia showed increased secretion of insulin at 2 hours of measurement. Giving indications of insulin secretion by administration of the aqueous extract of $C$. ficifolia. From the viewpoint 
phytochemical is proposed to D-chiro-inositol (DQI) as the molecule responsible for the effect of the fruit hypoglycemic $C$. ficifolia. In other studies, the decrease in blood glucose of rats with experimental diabetes was attributed to isolate $\mathrm{DCl}$ and C. ficifolia.

On the other hand, it has also shown that an aqueous extract of $I$. sonorae lowers blood glucose levels in healthy mice with experimental diabetes. In other studies, it was possible to demonstrate that blocking the $\mathrm{K}^{+}{ }_{\text {ATP }}$ channels in rat thoracic aorta, so it has been suggested that its hypoglycemic action mechanism may be associated with the secretion of insulin, similar to sulfonylureas. From the viewpoint phytochemical have been proposed several monoglycerides and fatty acids such as those responsible for hypoglycemic effect in a dichloromethane extract. As for the accused extract, is attributed to the effect cucurbitacins (oxygenated tetracyclic terpenoids). Thus, these plants represent a useful alternative to control DT2 available to most people. However, there is still a deeper understanding of its hypoglycemic effect. Quantification in insulin gene expression in cells treated with these extracts has not been investigated yet. The purpose of this investigation is to establish the influence of the extracts on the production and secretion of insulin in a cell culture secreting insulin (RINm5f).

\section{Methodology}

The cell line RINm5f (from rat insulinoma) was treated 24 hours with the aqueous extract of C. ficifolia $(0.25 \mathrm{M})$ and DQI $(0.25 \mathrm{M})$. Tested independently extract I. sonorae $(0.25 \mathrm{mg} / \mathrm{mL})$. Total RNA was extracted from treated cells was determined and insulin expression of Kir6.2 and real-time PCR. Additionally, 
insulin concentrations measured (by ELISA) and $\mathrm{Ca}^{2+}$ (by spectrophotometric method).

\section{Results}

C. ficifolia and $\mathrm{DCl}$ increased the insulin mRNA expression 6 and 4 times respectively ( $p \leq 0.0001)$ and Kir6.2 increased 150 fold $(p \leq 0.0001)$, both with $C$ ficifolia and $\mathrm{DCl}$. The intracellular concentration of $\mathrm{Ca}^{2+}$ increased $160 \%(p \leq$ 0.0056). Insulin secretion $11 \%$ ( $\leq \leq 0.007)$. Furthermore, $I$. sonorae reduced insulin gene expression 20\% ( $p \leq 0.0001)$, Kir6.2 expression showed no significant changes. The concentration of intracellular $\mathrm{Ca}^{2+}$ increased $80 \%(p \leq 0.001)$. Insulin secretion increased 35\% ( $1 \leq 0.0032)$.

\section{Conclusions}

It can be concluded that the hypoglycemic effect of the aqueous extract of $C$. ficifolia involves increased and Kir6.2 expression of insulin, insulin secretion and increased $\mathrm{Ca}^{2+}$. For its part, the aqueous extract of $I$. sonorae decreases insulin expression, without changes in Kir6.2. However, increases of intracellular $\mathrm{Ca}^{2+}$ concentration, with increased insulin secretion. 


\section{Í N D I C E}

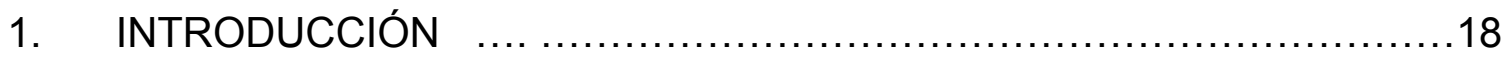

1.1. Definición y complicaciones de la diabetes mellitus (DM) ............... 18

1.2. Clasificación de la Diabetes Mellitus (DM) ....................................19

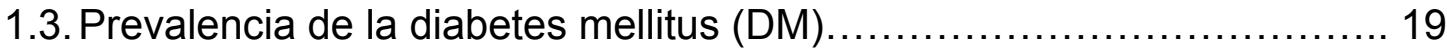

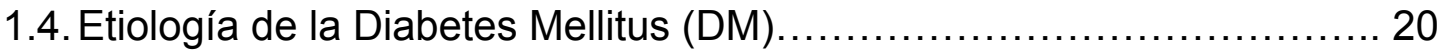

1.5. Mecanismos de secreción de insulina y regulación....................23

1.6. Mecanismo de acción de la insulina...............................29

1.7. Terapéutica medicamentosa de la diabetes..........................30

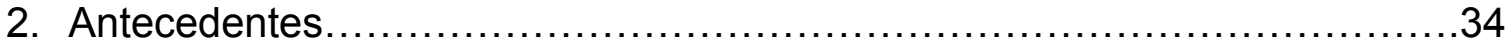

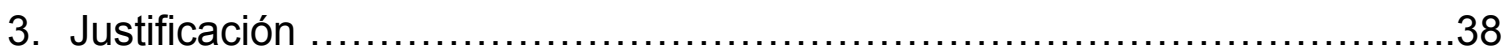

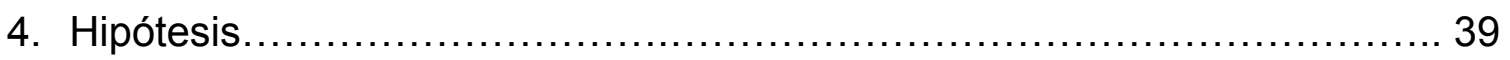

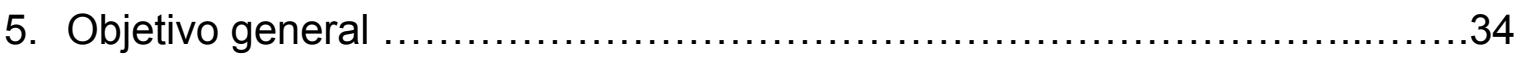

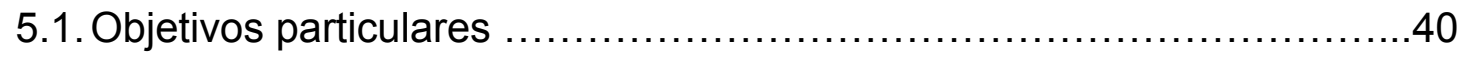

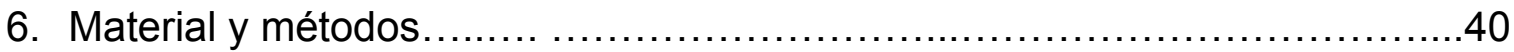

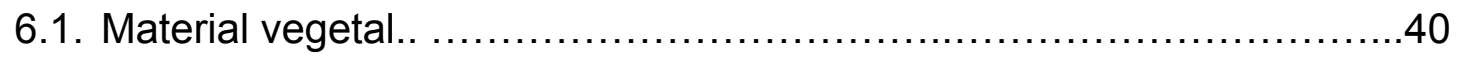

6.2. Obtención de los extractos acuosos..............................41

6.3. Análisis fitoquímico del extracto acuoso de $C$. ficifolia.................42

6.4. Cuantificación de polifenoles totales (Método Folin - Ciocalteau) en el extracto acuoso de I. sonorae.

6.5. Efecto hipoglucémico del extracto acuoso de Cucurbita ficifolia Bouché e Ibervillea sonorae Greene..........................................44

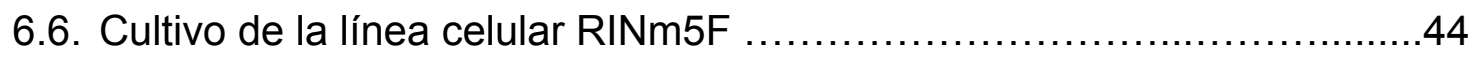


6.7. Viabilidad celular (Prueba de MTT) …................................ 45

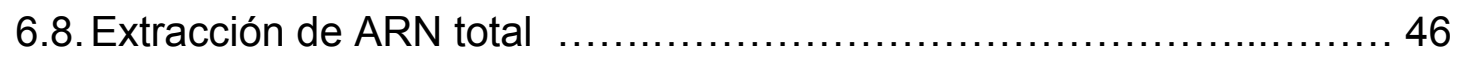

6.9. Cuantificación de la expresión del ARNm de insulina $\ldots \ldots \ldots \ldots \ldots \ldots \ldots . . . . . . .47$

6.10. Cuantificación de $\mathrm{Ca}^{2+}$ intracelular ............................... 48

6.11. Determinación del Contenido de Proteína............................. 49

6.12. Cuantificación de la secreción de insulina por el método de ELISA 49

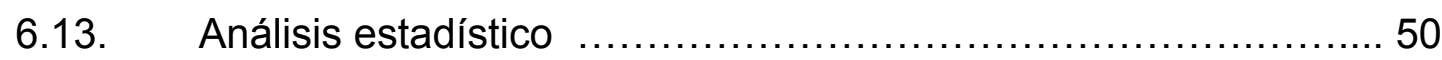

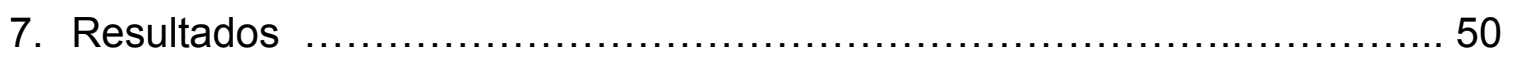

7.1. Cultivo de las células RINm5F ........................................ 50

7.2. Cuantificación de DQI y de polifenoles totales en el extracto acuso de $C$. ficifolia e I. sonorae, respectivamente.................................. 51

7.3. Efecto hipoglucémico del extracto acuoso de $C$. ficifolia.................. 51

7.4. Efecto hipoglucémico del extracto acuoso de $I$. sonorae .................. 52

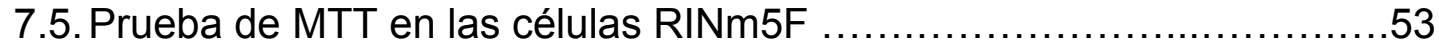

7.6. PCR en tiempo real para las células RINm5F......................... 55

7.7. Expresión del gen de insulina de las células RINm5F 56

7.8. Expresión del gen Kir 6.2 de las células RINm5F ................... 57

7.9. $\mathrm{Ca}^{2+}$ intracelular de las células RINm5F ............................. 58

7.10. Secreción de insulina de las células tratadas RINm5F ..........59

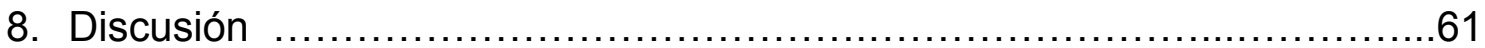

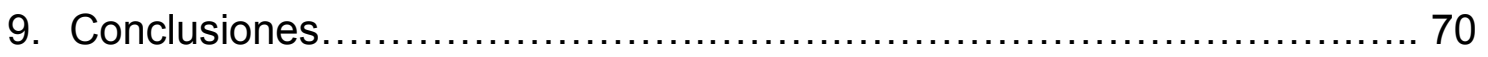

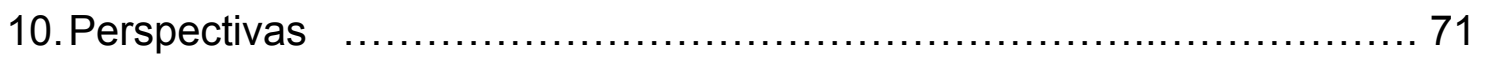


11. Referencias bibliográficas. 


\section{INTRODUCCIÓN}

\subsection{Definición y complicaciones de la diabetes mellitus (DM)}

La DM se define como un desorden metabólico de etiología múltiple caracterizada por hiperglucemia crónica. Las alteraciones del metabolismo de carbohidratos, grasas y proteínas, son resultado de defectos en la secreción y/o acción de la insulina (OMS, 1999).

Este padecimiento causa diversas complicaciones. Las complicaciones agudas incluyen hipoglucemia, cetoacidosis y coma hiperosmolar (en estas dos últimas participan síndromes virales, infecciones de tracto urinario neumonía, etc.) debido principalmente a un control inadecuado de la enfermedad (Chaithongdi y col., 2011). Por su parte, las complicaciones crónicas incluyen daño cardiovascular (Bradan y col., 2012) que se debe principalmente, al desarrollo temprano de cambios vasculares ateroscleróticos. Estos cambios vasculares son principalmente en músculo liso, endotelial y celular, así como rigidez arterial (Naka y col., 2012) y nefropatía (Börgeson y col., 2012). Los estudios han demostrado que la nefropatía diabética se asocia con la mortalidad cardiovascular. La hipertensión, un factor de riesgo bien establecido para las enfermedades cardiovasculares, contribuye a enfermedad renal terminal en la diabetes (Musabayane, 2012). La retinopatía diabética es un trastorno microvascular asociado con microaneurismas, hemorragias intrarretinianas, perfusión capilar y neovascularización (Gardner y col., 2012; Figuerola, 1997; D’Elia y col., 2011; Kerkeni y col., 2012). 


\subsection{Clasificación de la Diabetes Mellitus (DM)}

El Comité de expertos de la Asociación Americana de Diabetes (ADA), clasificó a la DM en 4 grupos (ADA., 2011):

a) Diabetes tipo 1 (DT1. Destrucción de las células, por lo general conduce a una deficiencia absoluta de insulina).

b) Diabetes tipo 2 (DT2. Resultado de un defecto en la secreción de insulina progresiva y resistencia a la insulina).

c) Diabetes gestacional. Se presenta en el embarazo y está caracterizada por resistencia a la insulina (Baci y col., 2012; Wang YH y col., 2012).

d) Otros tipos de DM (debidos a defectos genéticos en la función de las células . Defectos genéticos en la acción de la insulina. Enfermedades del páncreas exocrino (por ejemplo, fibrosis quística). Por químicos o drogas, tal como en la tratamiento del VIH/SIDA o después de un trasplante de órganos (ADA, 2011).

\subsection{Prevalencia de la diabetes mellitus (DM)}

Del 5 al 10\% de la población mundial tienen DT1, mientras que del 85 a 90\% de los casos, son de DT2 (Rorsman y col., 2012).

La Federación Internacional de Diabetes (IDF por sus siglas en inglés) estimó en el 2010, que México ocupó la décima posición entre los países con el mayor número de personas con DM (6.8 millones). Sin embargo, la información es 
inexacta, con base a los datos de la Encuesta Nacional de Salud y Nutrición 2006, existían 7.3 millones de casos (Aguilar-Salinas y col., 2011).

La incidencia nacional de DT2 por año es de 404,770 (Dirección General de Epidemiología (DGE), 2009) de los cuales $9.7 \%$ son mujeres y $8 \%$ hombres (Escobedo-de la Peña y col., 2011). Para un total, que oscila entre los 6.5 y 10 millones de pacientes (Federación Mexicana de Diabetes (FMD), 2009).

\subsection{Etiología de la Diabetes Mellitus (DM)}

La DT1 se desencadena por la destrucción progresiva de las células de los Islotes de Langerhans debido a un proceso autoinmune (Ferreira y col., 2012). Este fenómeno disminuye hasta un $90 \%$ la masa y la función de las células . La prevalencia de DT1 es mayor en personas que presentan ciertos antígenos del complejo mayor de histocompatibilidad (HLA Human Leucocyte Antigen), localizados en el cromosoma 6 y que regulan la respuesta inmune. La presencia de los antígenos HLA, DR3, DR4, DQA Arg 50 y DBQ predisponen el desarrollo de la enfermedad, aunado al efecto de otros factores ambientales como virus, sustancias tóxicas u otros inmunogénicos (Notkins, 2002). Si bien, la contribución directa de anticuerpos a la patogénesis de la enfermedad es controvertida. La isoforma más pequeña de glutamato descarboxilasa (GAD65) está implicada como un autoantígeno. Éste contribuye de manera importante en la patogénesis de la destrucción de las células . Autoanticuerpos dirigidos a GAD65 (GAD65Ab) están presentes en la mayoría de los pacientes de inicio de DT1 (Giuliani y col., 2009). En general se reconoce que el mecanismo de destrucción de las células está mediado por las células T autorreactivas que habían escapado a la selección 
tímica. Los autoanticuerpos contra la isoforma de $65 \mathrm{kd}$ de glutamato descarboxilasa (GAD65Ab) son marcadores humorales de la respuesta autoinmune de DT1. Sin embargo, hallazgos recientes sugieren que GAD65Ab existe también en individuos sanos, en donde se bloquea su unión a GAD65 por anticuerpos específicos anti-idiotípicos (anti-Id). La concentración sérica de GAD65Ab específicos anti-Id en pacientes con DT1 es significativamente menor en comparación a la de los individuos sanos (Wang Xin y col., 2012).

Por otro lado, uno de los primeros eventos que conducen a DT2, es la resistencia a la insulina (RI), generalmente asociada con la obesidad (Barbarroja y col., 2012). Una respuesta inflamatoria, aumento del nivel de daño oxidativo del ADN, la condición de hiperglucemia y la generación de especies reactivas de oxígeno (ROS) son la causa del daño al ADN (Manoel-Caetano y col., 2012).

La RI lleva a un incremento de la síntesis y secreción de insulina (Eckel y col., 2011). La hiperinsulinemia compensatoria, es capaz de mantener la homeostasis metabólica por años (Eckel y col., 2011). Los individuos con intolerancia a la glucosa y los diabéticos de corta evolución son hiperinsulinémicos, característica típica de RI (De Cosmo y col., 2012). En combinación con diversos factores como sobrepeso, hipercolesterolemia, hipertrigliceridemia, hipertensión, hiperglucemia, etc., establecen el síndrome metabólico (Povel y col., 2012), que puede anteceder al desarrollo de DT2 (Figuerola, 1997; Gaddam y col., 2011; Olokoba y col., 2012).

La obesidad y el sedentarismo son factores que acentúan la RI (Meyer y col., 2011). La obesidad, predominantemente abdominal, lleva a una mayor secreción 
de ácidos grasos libres y desregulación en la producción de citocinas. Aumento de la producción de adipocinas/citoquinas, incluyendo factor de necrosis tumoral, resistina y la proteína de unión al retinol 4. Así como niveles reducidos de adiponectina, las cuales establecen un perfil inflamatorio típico que conduce al desarrollo de RI (Eckel y col., 2011). El inicio de la DT2, tiene un carácter irreversible en la mayoría de los casos. Está asociada a RI, obesidad y a defectos en las células . La capacidad de las células para liberar insulina en respuesta a glucosa es de suma importancia en la homeostasis de la glucosa en sangre. Estudios recientes en humanos y roedores apoyan el concepto de que las alteraciones en las células del páncreas conllevan a la DT2 (Martin-Gronert y col., 2012; Triplitt., 2012). La disminución en su masa y volumen debido a la disfunción de la mitocondria causa estrés oxidante, así como disminución de la síntesis de ATP (Nguyen y col., 2011). El incremento en la apoptosis, que no se compensa adecuadamente por la regeneración de estas células causa DT2 (Marchetti y col., 2010). El adecuado funcionamiento del retículo endolpásmico (RE) es indispensable para las células pancreáticas. El estrés en este organelo es un factor que contribuye a la muerte de estas células en DT2 (Kirkpatrick y col., 2011; Bartolome y col., 2012).

Los factores genéticos juegan un papel importante en el desarrollo de la DT2 (Gamboa-Meléndez y col., 2012; Khan y col., 2012). El gen HMGA1 está involucrado en la patogénesis de la resistencia a la insulina y DT2. Variantes genéticas de HMGA1 (por sus siglas en inglés: Variants of high-mobility group A1) son capaces de reducir los niveles intracelulares del receptor de insulina en los 
tejidos diana de insulina (Brunetti y col., 2011). Otro de los genes de riesgo más reproducibles es cdkal1 (por sus siglas en inglés: cyclin-dependent kinase 5 regulatory subunit associated protein 1-like 1) (Fu y col., 2012). Variaciones en este gen están asociadas con disminución en la secreción de insulina. En las células pancreáticas de ratones deficientes de Cdkal1, se observa deterioro en la generación de ATP miocondrial. Los islotes pancreáticos muestran hipertrofia y deterioro del control de glucosa en sangre. Además los ratones son hipersensibles a dieta alta en grasa, generando estrés del RE (Wei y col., 2011). Los microRNA (miRNA), constituyen una creciente clase de RNA no codificantes que regulan la expresión génica por represión de la transcripción. Los miRNAs juegan un papel importante en DT2 (Poy y col., 2004). El miR-96, regula negativamente la exocitosis de la insulina (Fernández-Valverde y col., 2011).

Los receptores $X$ del hígado (LXR)- $y$, desempeñan un papel crucial en el control de la producción y secreción de insulina las células . Las variantes de genes como NR1H2 y NR1H3, pueden alterar la función de las células del páncreas (Ketterer y col., 2011). En un estudio europeo en pacientes con DT2; la variante rs2248949 del gen NR1H2 se asoció normalmente con resistencia a la insulina. La deficiencia en el gen NR1H2 facilitó el desarrollo de DT2 (Ketterer y col., 2011).

\subsection{Mecanismos de secreción de insulina y regulación}

La secreción de insulina es estimulada directamente por glucosa, secretagogos no glucocídicos (aminoácidos y lípidos), hormonas insulinotropas y 
neurotransmisores. Los aminoácidos, principalmente arginina, leucina y lisina, son capaces de estimular la secreción de insulina. Los metabolitos de aminoácidos como fenilpiruvato, -cetoisocaproato, -cetocaproato o -ceto- -metilvalerato también son estimuladores potentes de la secreción de insulina (Montanya y col., 2007). La exposición prolongada de ácidos grasos libres inhiben la secreción de insulina estimulada por glucosa (Juhl y col., 2002).

Los factores clave en el proceso de secreción de insulina son:

$>$ El transportador de glucosa transmembranal GLUT 1 y 3 en humanos y GLUT2 en roedores.

$>$ Canales específicos de $\mathrm{K}^{+}$dependientes de ATP.

$>$ Canales de calcio $\left(\mathrm{Ca}^{2+}\right)$ dependientes de voltaje que favorecen la liberación de los gránulos de insulina.

Cuando la concentración de glucosa aumenta entre 4-8 mM en el plasma, ingresa en la célula a través del transportador GLUT1, GLUT2 o GLUT3 (dependiendo del organismo) (Rorsman y col., 2012). La glucosa se metaboliza a glucosa-6-fosfato por la glucocinasa, cuyo gen está regulado por insulina. Posteriormente el nivel intracelular de ATP aumenta como consecuencia del metabolismo de la glucosa. Los canales de $\mathrm{K}^{+}$se encuentran abiertos en condiciones usuales de ATP. Contribuyen de forma sustancial a mantener el potencial de membrana en reposo de las células. Cuando el nivel de ATP aumenta; el canal de $\mathrm{K}^{+}$dependiente de ATP $\left(\mathrm{K}^{+}{ }_{\text {ATP }}\right)$ de la subfamilia Kir6.2 se cierra. La salida de este ion se ve alterada. Con este fenómeno, la membrana 
plasmática de la célula se despolariza hasta alcanzar un voltaje en el que se activan los canales de calcio $\left(\mathrm{Ca}^{2+}\right)$ dependientes de voltaje. La apertura del canal permite la entrada de $\mathrm{Ca}^{2+}$ y desencadena la movilización y liberación de los gránulos de insulina. La activación de fosfolipasa C, formación de IP3 y diacilglicerol (DAG) son dependientes del aumento en la concentración de $\mathrm{Ca}^{2+}$. El aumento en las concentraciones intracelulares de $\mathrm{Ca}^{2+}$, también pueden aumentar la activación de la proteína cinasa C (PKC). Estos mediadores participan en la secreción de insulina (Yamazaki y col., 2010).

Adicionalmente, diversas hormonas regulan la secreción de insulina. Una de las vías que potencia la secreción de insulina, es la activación de proteína cinasa A (PKA), mediante la unión de hormonas a su receptor acoplados a proteína $G$, presentes en la célula (Itoh y col., 2003). Así, el glucagón la estimula y la somatostatina la inhibe. Las hormonas gastrointestinales como GLP-1 (péptido semejante al glucagón 1) y el GIP (polipéptido insulinotrófico dependiente de glucosa) estimulan la secreción de insulina mediante la unión a su receptor acoplado a una proteína G; en respuesta a la ingesta de alimentos (Gagliardino y col., 2005).

La Figura 1, integra las vías de secreción de insulina. La entrada de glucosa a la célula es mediante el transportador GLUT-2 (roedores). La célula es muy sensible a la glucosa debido a las altas concentraciones de la glucocinasa. Enzima que informa a la célula de cualquier cambio en el nivel de glucosa debido a que la fosforila para su metabolismo (A). Cuando aumenta la concentración de glucosa en la célula ; la célula acelera su metabolismo, lo que lleva al cierre de 
los canales $\mathrm{K}_{\text {ATP }}^{+}$en la membrana plasmática $(\mathrm{B})$. Estos canales están compuestos por un poro llamado Kir6.2 y por un receptor de sulfonilurea (SUR1). La unión intracelular de ATP al canal de $\mathrm{K}^{+}$ATP lo cierra y esto induce la apertura del canal de $\mathrm{Ca}^{2+}$; lo que conlleva a la entrada de este ión al citoplasma de la célula $(\mathrm{C})$.

El aumento en la concentración de $\mathrm{Ca}^{2+}$ regula una serie de eventos (D). Por un lado, la exocitosis de insulina mediada por segundos mensajeros dependientes de $\mathrm{Ca}^{2+}$, como la PLC (E). La PLC se encarga de hidrolizar al fosfatidilinositol bifosfato $\left(\mathrm{PIP}_{2}\right)$ en DAG e IP $(\mathrm{F})$. Por otro lado, el DAG activa a PKC que también puede activarse por $\mathrm{Ca}^{2+}$ libre del citoplasma e induce la exocitosis de la insulina (G). Por su parte, el $\mathrm{IP}_{3}$ entra al RE para liberar más $\mathrm{Ca}^{2+}$ al citoplasma $(\mathrm{H})$. La PLC también puede activarse por un agente extracelular que se une a un receptor de superficie celular (I).

La activación del sistema parasimpático estimula la secreción de insulina y glucagón, mientras que la activación de receptores -adrenérgicos la inhiben y los -adrenérgicos la estimulan. Además, los neurotransmisores como acetilcolina, por lo general, potencian la secreción de insulina por una doble acción. Aumentan moderadamente la señal de disparo, es decir, aumento de $\mathrm{Ca}^{2+}$ intracelular. La acetilcolina es secretada por el nervio vago en respuesta tanto en la anticipación de una comida como en su digestión. La acetilcolina se une a su receptor activando a una proteína $\mathrm{G}$ acoplada. El resultado es un cambio conformacional disociando la subunidad de la proteína G que estimula a la PLC, la cual hidroliza el PIP 2 (I) (Henquin, 2004; Yamazaki y col., 2010). 
Las hormonas como el GLP-1 y el GIP se unen a su receptor acoplado a proteínas G, transmitiendo una señal a la adenilato ciclasa. Esta enzima genera AMP cíclico a partir de ATP. El AMP cíclico interacciona con la PKC, activándola e induciendo así la secreción de insulina. Así mismo, La activación de la PKA o PKC aumenta la eficacia de la exocitosis de insulina mediada por $\mathrm{Ca}^{2+}$ intracelular (J) (Yamazaki y col., 2010).

Estos mecanismos bioquímicos tienen un tipo de amplificación distinto de los involucrados en la vía de amplificación de la glucosa y otros nutrientes. Por último, las hormonas y los neurotransmisores inhibitorios también actúan a través de dos vías. Deprimen la secreción de insulina, en parte por la disminución de la señal de disparo (a través de la repolarización de la membrana). La reducción de $\mathrm{Ca}^{2+}$ (inhibición a través de cinasas o de proteínas $\mathrm{G}$ ) disminuye la secreción de insulina. De manera específica, la adenilato ciclasa puede ser activada o inhibida por las proteínas $\mathrm{G}$ que están acopladas a proteínas de membrana dependiendo el estímulo hormonal. La somastatina (K) es un ligando inhibidor (Henquin, 2004; Yamazaki y col., 2010). 


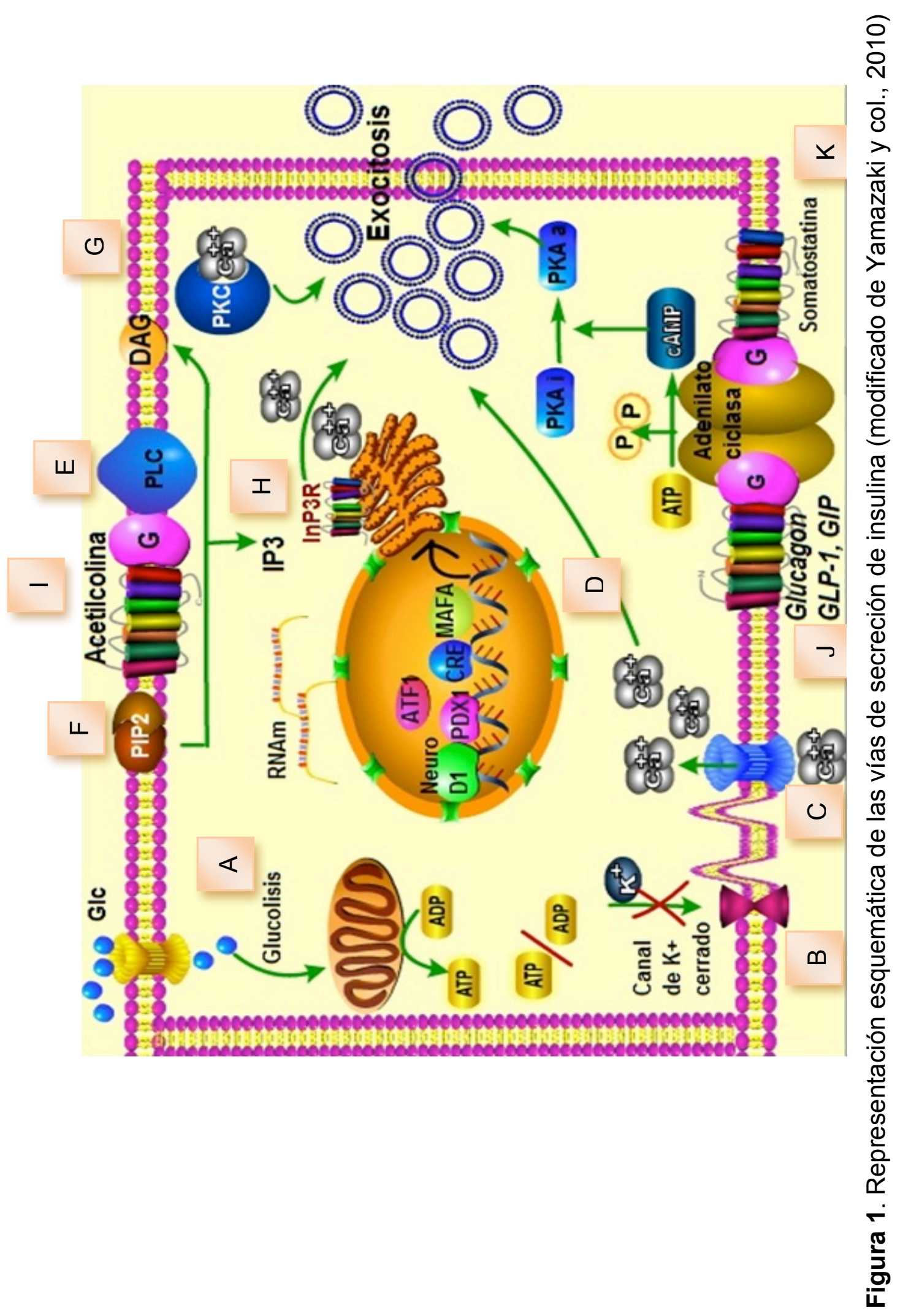




\subsection{Mecanismo de acción de la insulina}

La insulina se fija selectivamente a la subunidad de su receptor; como consecuencia de esta fijación, la subunidad se autofosforila. En preparaciones de receptores insulínicos aislados, la fosforilación ocurre exclusivamente en los residuos de tirosina, mientras que en células intactas se aprecia también en los aminoácidos serina y treonina (Florez y col., 1997). Dos vías principales de transducción son activadas por acción de la insulina: la vía de la fosfatidilinositol 3-cinasa (PI3K) y la vía de las cinasas activadas por mitógenos (MAP cinasas). Ambas vías regulan la mayoría de las acciones de la insulina asociadas a la regulación del metabolismo energético, de la expresión genética y de efectos mitogénicos El receptor de insulina, además de autofosforilarse, fosforila a otras proteínas citosólicas llamadas sustratos 1 y 2 del receptor de insulina (IRS1, IRS2) en sus residuos de tirosina. Posteriormente, los sustratos se fijarán a dominios $\mathrm{SH} 2$ de otras proteínas (p. ej., GRB2) y éstas a la proteína Sos, hasta conseguir la activación de Ras y la cascada de las MAPcinasas. (Reyes y col., 2008). La vía de la PI3K es el principal mecanismo por el que la insulina ejerce sus funciones en el metabolismo de la glucosa y de lípidos. La transducción de señales a través de la vía de PI3K se inicia cuando el receptor activo y autofosforilado, interacciona con IRS y lo fosforila. Las proteínas IRS contienen un dominio amino-terminal de homología a pleckstrina (dominio $\mathrm{PH}$ ) altamente conservado, seguido por un dominio de unión a fosfotirosinas (PTB), que en conjunto permiten el acoplamiento de IRS al IRS activo. Adicionalmente, los IRSs 
contienen entre 8 y 18 sitios potenciales de fosforilación (en función del tipo de IRS, de los cuales se conocen 4 isoformas, IRS-1 a IRS-4), que al ser fosforilados por el IR, se convierten en sitios de unión y activación de proteínas que contienen dominios SH2 (de homología al dominio 2 de la proteína Src). Muchas de las cuales funcionan como proteínas adaptadoras, como es el caso de PI3K, Grb2 (proteína 2 unida al receptor del factor de crecimiento), Crk II, SHP-2 (proteína tirosina fosfatasa con homología a Src) (Reyes y col., 2008). La acción celular de la insulina es pleiotrópica, es decir, se manifiesta en forma de un conjunto de acciones celulares que involucran muy diversas funciones con una determinada secuencia temporal. En cuestión de minutos se aprecia la activación del transporte de hexosas (glucosa), modificaciones en la regulación de genes y la fosforilación del receptor insulínico por parte de otras cinasas. Todos estos efectos no requieren la síntesis de nuevas proteínas. Finalmente, si se mantiene el contacto con la insulina, aparecen las acciones tardías, como síntesis de ADN y ARN, proteínas y lípidos e influencia sobre el crecimiento celular (Florez y col., 1997; Choi y col., 2010).

\subsection{Terapéutica medicamentosa de la diabetes}

La terapéutica farmacológica de la diabetes se centra en dos objetivos íntimamente relacionados: a) mejorar la utilización de la glucosa y otros nutrientes en los tejidos (aminoácidos, glicerol, ácidos grasos y cuerpos cetónicos) y b)

normalizar al máximo posible los niveles de glucemia sin perturbar de manera notable el estilo de vida de quien la padece (Gagliardino, 2005). La pioglitazona y 
metformina son sensibilizadores de insulina usados para el tratamiento de la DT2 (Naka y col., 2012). La metformina y la fenformina, se administran casi siempre en combinación con una sulfonilurea. Su mecanismo de acción incluye la inhibición de la gluconeogénesis hepática e incremento de la disponibilidad de la glucosa en músculo y tejido adiposo. Tienen la ventaja de que no producen hipoglucemia, pero en algunos casos provocan acidosis láctica, por lo que no se deben administrar cuando hay lesión hepática. (Figuerola, 1997).

Entre los principales hipoglucemiantes orales existentes para el tratamiento de la enfermedad se encuentran las sulfonilureas. Actúan sobre las células inhibiendo el canal de $\mathrm{K}^{+}$ATP y la salida de $\mathrm{K}^{+}$, lo que induce la despolarización de la membrana y la entrada de $\mathrm{Ca}^{2+}$ extracelular (Proks y col., 2002. Favorecen la exocitosis de los gránulos de insulina. Las sulfonilureas incrementan la sensibilidad de las células a la glucosa, estimulándolas a incrementar la secreción de insulina. Las sulfonilureas sólo pueden ser usadas en pacientes con DT2, debido a que en la DT1 la masa de las células , es casi nula (Willenborg y col., 2011).

Las tiazolidinedionas, incluyen una serie de nuevos fármacos como, roziglitazona y pioglitazona, entre otras. Estos fármacos están dirigidos a reducir la $\mathrm{RI}$ e incrementar la actividad del receptor de insulina. A pesar de las grandes expectativas iniciales en algunos de estos medicamentos, sus efectos secundarios adversos han sido motivo de que algunos sean retirados del mercado (Figuerola, 1997; Choi y col., 2010; Krentz y col., 2012). 
Los inhibidores de la dipeptidil peptidasa 4 (DPP-4), como la sitagliptina (Cerra y col., 2012) y linagliptina (Ishiguro y col., 2012), son miembros de una clase de agentes hipoglucemiantes orales, una nueva opción de tratamiento de la DT2. Los inhibidores de DPP-4 inhiben la peptidasa de serina DPP-4, que es responsable de la escisión rápida de las hormonas incretinas endógenas, como GLP-1 y el GIP in vivo. Después de la ingesta de alimentos, GLP-1 y GIP regulan la secreción de la insulina. La secreción de glucagón también es reducida por GLP-1, que a su vez reduce la gluconeogénesis hepática. La prolongación de la vida media de estas incretinas aumenta la secreción de insulina dependiente de glucosa. Inhibe la producción de glucosa endógena y disminuye la glucosa en sangre (Hoimark y col., 2012; Russell-Jones y col., 2012).

En relación con la terapia farmacológica, la insulina es una hormona hipoglucemiante, utilizada con mayor efectividad para disminuir la glucosa en sangre. Es un polipéptido de 51 aminoácidos (5,8 kD) sintetizado por las células del páncreas. Consta de dos cadenas, la con 21 y la con 30 aminoácidos, unidos entre sí por dos puentes disulfuro (Florez y col. 1997). La administración de insulina exógena representa una buena alternativa terapéutica, pero se emplea sólo cuando el resto de hipoglucemiantes ha perdido su efecto (Figuerola, 1997). A pesar del amplio uso de estos medicamentos aún no se ha demostrado de manera concluyente su eficacia para evitar el desarrollo de las complicaciones cardiovasculares e inclusive se ha llegado a asegurar que aumentan la incidencia de éstas (Figuerola, 1997). Además, muchos pacientes no sólo intentan controlar su enfermedad con la administración de estos medicamentos, sino también acuden al uso de remedios herbolarios, los cuales, ya sea solos o en combinación 
con los medicamentos de patente, son altamente consumidos. De hecho, se tienen reportes que más del $64 \%$ de la población mundial recurre a la medicina tradicional, como única alternativa a su alcance, para resolver sus problemas de salud (Farnsworth y col., 1995).

En nuestro país el uso de plantas medicinales es tan amplio como ancestral. El conocimiento y uso de plantas medicinales es de primordial relevancia en comunidades rurales, sobretodo indígenas, quienes durante siglos han preservado sus conocimientos empíricos sobre las propiedades curativas de las plantas, transmitiéndolas a lo largo de generaciones. Existen plantas que se utilizan como antiinflamatorias, anticancerígenas, antivirales, antibacteriales, antidiabéticas, antioxidantes, etc. En el caso particular de la diabetes, se tienen reportes del uso de más de 350 plantas para el control empírico de DT2 (Romero y col., 2009).

Dentro del grupo de plantas que se emplean como remedio antidiabético, destacan Cucurbita ficifolia Bouché (C. ficifolia) e Ibervilliea sonorae Greene (I. sonorae). Dos especies de la familia Cucurbitaceae ampliamente estudiadas en México. Estas plantas representan una alternativa útil en el control de la DT2 al alcance de la mayoría de la población. Además se consideran una fuente potencial de materia prima para la obtención de nuevos fármacos hipoglucemiantes orales. Sin embargo, su investigación experimental y clínica en nuestro país es todavía preliminar y aún no se conocen los mecanismos de acción hipoglucemiante. 


\section{Antecedentes}

\section{Cucurbita ficifolia Bouché (C. ficifolia)}

Se han realizado diversos estudios en C. ficifolia, conocida en México como "chilacayote". La planta se cultiva por sus frutos comestibles. El efecto hipoglucémico del fruto de $C$. ficifolia se ha estudiado en diversos modelos como: ratas, ratones y conejos. Los estudios realizados con ratones sanos a los que se administraron $500 \mathrm{mg} / \mathrm{Kg}$ peso del jugo de C. ficifolia vía intraperitoneal y oral, demostraron su efecto hipoglucémico (disminución de hasta $50 \mathrm{mg} / \mathrm{dl}$ ). Este efecto también se observó en ratas con aloxana bajo un esquema de tratamiento que involucra la administración diaria (500 mg/Kg de peso), vía oral, del jugo de C. ficifolia durante 14 días (disminución de glucosa de manera progresiva; de hasta 50 mg/dl) (Alarcón y col., 2002).

La administración oral de C. ficifolia $(4 \mathrm{ml} / \mathrm{kg}$ ), en pacientes con DT2 (con glucemias de entre 150-300 mg/dl), mostró disminución de glucosa en sangre de estos pacientes después de $3 \mathrm{~h}$ de tomar el extracto (Acosta y col., 2001).

En otro estudio se midió la capacidad de este extracto para bloquear los canales $\mathrm{K}_{\mathrm{ATP}}^{+}$, en aorta torácica de rata. Con este estudio, se estableció si el efecto hipoglucémico del extracto acuoso de C. ficifolia podría estar asociado con la secreción de insulina, de manera similar a las sulfonilureas. Sin embargo, los resultados fueron negativos (Banderas-Dorantes, 2012).

En suma, el fruto de C. ficifolia es comúnmente usado como un agente antidiabético. Sin embargo, su efecto hipoglucémico es desconocido. En este 
sentido, el presente trabajo está dirigido a determinar si el efecto hipoglucémico de C. ficifolia involucra la producción y secreción de insulina.

Desde el punto de vista fitoquímico, se propuso al D-quiro inositol (DQI) como la molécula responsable del efecto hipoglucémico del fruto de C. ficifolia. Un monitoreo en la progresión de ratones sanos, a ratones con obesidad-no diabéticos, mostró mayor excreción urinaria progresiva de myo-inositol (precursor de DQI), aunado a una disminución urinaria progresiva de DQI. Este patrón de excreción alterado, se observó en monos obesos-no diabéticos. Sugiriendo que, estos cambios se dan en función de la resistencia a la insulina (Larner., 2001). En otro estudio, el decremento de glucosa en sangre de ratas con diabetes experimental, se le atribuyó al DQI aislado de C. ficifolia (Xia y col., 2006).

Un estudio evaluó los efectos antidiabéticos del extracto acuoso del fruto de $C$. ficifolia, en un modelo experimental de ratas con diabetes inducida por administración de estreptozotocina. La administración oral de extracto acuoso del fruto de C. ficifolia (10 y $20 \mathrm{mg}$ de extracto de $C$. ficifolia, con base en el contenido de DQI/kg; durante 30 días), causó disminución significativa de glucosa en sangre. Además de aumentar los niveles de glucógeno hepático, hemoglobina total e insulina plasmática (Xia y col., 2006).

Adicionalmente, el análisis histológico de páncreas de ratones que recibieron $C$. ficifolia reveló un incremento en el número de islotes pancreáticos. Proponiendo que las células pancreáticas expuestas a diferentes dosis de C. ficifolia aumenta su proliferación, la producción y liberación de insulina, lo cual podría explicar el efecto hipoglucémico de C. ficifolia (García-Gonzalez, 2009). 
Ibervillea sonorae Greene (I. sonorae)

La raíz de $I$. sonorae, o "wareque" es también ampliamente utilizada en la medicina tradicional mexicana para el control de la DM. Es una planta dioica perenne. Pertenece a la familia Cucurbitaceae. Se localiza en zonas semiáridas de los estados de Sinaloa, Sonora y Baja California. Algunos grupos étnicos usan la raíz con múltiples propósitos: antirreumático, antiinflamatorio, analgésico, cardiotónico y se dice que es efectiva para curar el cáncer y como antidiabética (Alarcón y col., 2005). En un estudio in vivo se administró de manera aguda y crónica tanto la preparación tradicional (decocción acuosa) como el extracto crudo (jugo) de la raíz, dando como resultado reducciones significativas de la glucemia en ratones sanos tras la administración intraperitoneal $(600 \mathrm{mg} / \mathrm{kg}$ para ambos extractos). Así mismo, la dosis de $300 \mathrm{mg} / \mathrm{kg} / \mathrm{día}$ por vía oral a ratas diabéticas causó mejora significativa en el peso corporal, en la glucemia y en la trigliceridemia, en comparación con el grupo diabético que no recibió el extracto. El colesterol total y los niveles de ácido úrico no se vieron afectados (Alarcon y col., 2005).

En otro estudio se midió la capacidad de este extracto para bloquear los canales de $\mathrm{K}_{\text {ATP, }}^{+}$en aorta torácica de rata. Con este estudio, se estableció si el efecto hipoglucémico del extracto acuoso de I. sonorae podría estar asociado con la secreción de insulina, de manera similar a las sulfonilureas. El resultado fue positivo (Banderas-Dorantes, 2012). 
Desde el punto de vista fitoquímico se ha propuesto una mezcla de once monoglicéridos (MG) y cinco ácidos grasos (AG), incluyendo los ácidos láurico, mirístico, pentadecanoico, palmítico y esteárico, como la responsable del efecto hipoglucémico. La actividad observada en el extracto diclorometánico (administrada por vía intraperitonial en ratones sanos a una dosis de $300 \mathrm{mg} / \mathrm{kg}$ ) y por la mezcla obtenida de la raíz de I. sonorae de MG-AG (administrada por vía intraperitonial en ratones sanos de $150 \mathrm{mg} / \mathrm{Kg}$ ) apoya el uso popular de esta planta en el tratamiento de la diabetes en la medicina tradicional mexicana (Hernández y col., 2007).

Además, en estudios recientes se ha demostrado que I. sonorae induce el cierre de canales de $\mathrm{K}_{\text {ATP }}^{+}$en tejido aislado de aorta de rata (Banderas-Dorantesl, 2012). Estos datos nos permiten suponer que el mecanismo de acción hipoglucémico de esta planta es, inducir el cierre de los canales de $\mathrm{K}^{+}$ATP . Por tal motivo, la administración del extracto de $l$. sonorae aumentaría las concentraciones intracelulares de $\mathrm{Ca}^{2+}$, así como la liberación de insulina en células del páncreas tratadas con el extracto.

\section{Justificación}

La diabetes es un problema mundial y en México la incidencia, prevalencia y mortalidad están incrementándose a un ritmo acelerado. La diabetes se presenta en etapas cada vez más tempranas de la vida, con el consecuente incremento de las complicaciones. 
La DT2 se considera como la patología de índole endocrina más frecuente y una de las principales causas de morbilidad y mortalidad en México. Además, la diabetes y sus complicaciones tienen un importante impacto económico en quienes la padecen, sus familias, los sistemas de salud y los países. La Organización Mundial de la Salud (OMS) estima que entre 4 y $5 \%$ de los presupuestos de salud se gastan en las enfermedades relacionadas con diabetes. Los gastos médicos de una persona con diabetes son dos a cinco veces más altos que los de una persona sin esta enfermedad. Esta es la causa de la mayor parte de las visitas médicas, la razón principal de adquisición de aditamentos médicos y de medicamentos, así como la primera causa de ingreso a los hospitales.

Las alternativas terapéuticas para el tratamiento de esta enfermedad no son curativas y hasta el momento no se ha encontrado ninguna terapia alternativa que lo sea. Además, a pesar de tener una terapia farmacológica, los pacientes siguen utilizando plantas con propiedades antidiabéticas como alternativa de tratamiento para su enfermedad. Por esta razón, las plantas medicinales representan una fuente de materia prima para la búsqueda de nuevas sustancias o mezclas de sustancias que permitan ofrecer alternativas novedosas de tratamiento para el paciente. Sin embargo, antes de iniciar su estudio a nivel clínico, es necesario conocer los posibles efectos por los cuales estas plantas ejercen su efecto hipoglucémico a nivel experimental, a través de la investigación científica.

C. ficifolia contiene DQI e I. sonorae contiene glicéridos y ácidos grasos. Dichos compuestos se han propuesto como los responsables del efecto hipoglucémico. Sin embargo, no se conocen aún los mecanismos de acción hipoglucemiante. 
Considerando que que $I$. sonorea bloquea los canales de $\mathrm{K}_{\text {ATP y }}^{+}$que $C$. ficifolia promueve un aparente incremento en la densidad celular, los resultados obtenidos ampliarán el conocimiento acerca de la acción hipoglucemiante de estas plantas antidiabéticas. Se aportará evidencia a nivel molecular de sus efectos benéficos en la diabetes. Además, de apoyar la idea del desarrollo de nuevos medicamentos o fitofármacos con aplicación clínica, con un conocimiento científico que sustente su uso en el control de la diabetes.

\section{Hipótesis:}

C. ficifolia e I. sonorae descienden los niveles de glucosa en animales sanos y diabéticos. Por lo tanto, su acción hipoglucemiante debe estar mediada por el aumento en la síntesis y secreción de insulina.

\section{Objetivo general:}

Determinar la participación de la síntesis y liberación de insulina en el efecto hipoglucémico de las dos cucurbitáceas en la línea RINm5F.

\subsection{Objetivos particulares}

Demostrar en células RINm5F que los extractos hipoglucemiantes de $C$. ficifolia e I. Sonorae:

> Inducen la expresión del RNAm de insulina y Kir6. 
> Incrementan el contenido de $\mathrm{Ca}^{2+}$ intracelular.

Aumentan la secreción de insulina.

\section{Material y métodos}

\subsection{Material vegetal}

El fruto maduro de Cucurbita ficifolia se colectó en el municipio de Acolman, Estado de México (Septiembre). El diámetro del fruto fue de $21.5 \mathrm{~cm}$; longitud de la semilla: $1.6 \mathrm{~cm}$. La identificación taxonómica se hizo por medio del cotejo de las hojas de la planta colectada con ejemplares del herbario de plantas medicinales del IMSS (Herbario-IMSSM).

La raíz de I. sonorae se colectó en el poblado de Carbó en el estado de Sonora, en enero, abril y septiembre. El peso aproximado de cada tubérculo colectado fue de $2.5 \mathrm{~kg}$. La identificación botánica de la especie se realizó por medio del cotejo de ejemplares del herbario-IMSSM y MEXU (UNAM).

Para la obtención de los extractos se siguió la metodología de Contreras-Weber y col., 2002; Alarcón-Aguilar y col., 2002; Hernandez y col., 2007.

\subsection{Obtención de los extractos acuosos}

Cucurbita ficifolia Bouché (C. ficifolia) 
Se utilizó únicamente el endocarpio del fruto libre de semillas, el cual fue cortado en rebanadas delgadas que se colocaron en un recipiente para su deshidratación a temperatura ambiente y con aireación constante. El material seco se trituró en un molino eléctrico marca Turmix, usando una rejilla de $1 \mathrm{~mm}$ de diámetro. Se tomaron $100 \mathrm{~g}$ del fruto seco de C. ficifolia y se sometieron a maceración con agua $(1 \mathrm{~L})$ durante 72 horas dentro de una campana de flujo laminar con aeración constante. Cada 24 horas se recuperó la fase acuosa, la cual fue liofilizada (8 h/día). El producto resultante, se utilizó en los experimentos correspondientes (Figura 2).

Ibervillea sonorae Greene (I. sonorae)

La raíz de $I$. sonorae se cortó en rebanadas delgadas que se colocaron en un recipiente para su deshidratación a temperatura ambiente y con aireación constante. El material seco se trituró en un molino eléctrico marca Turmix, usando una rejilla de $1 \mathrm{~mm}$ de diámetro. Se tomaron $50 \mathrm{~g}$ de la raíz seca de $\mathrm{l}$. sonorae y fue sometida a decocción en $1 \mathrm{~L}$ de agua durante 10 minutos. El producto se colocó durante 72 horas dentro de una campana de extracción con aeración constante, la cual fue liofilizada (8 horas/día). El producto resultante, con rendimiento del 10\%, se utilizó en los experimentos correspondientes (Figura 3). 


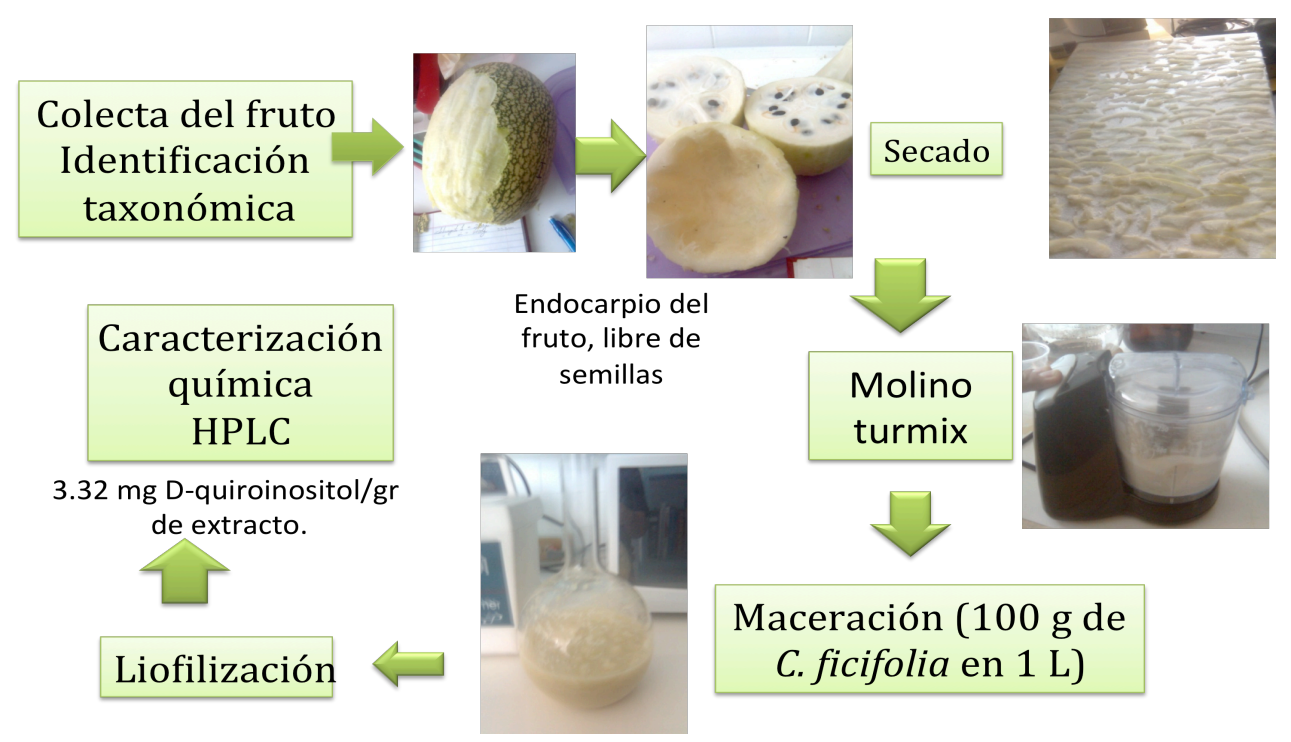

Figura 2. Obtención del extracto acuoso de C. ficifolia.

\subsection{Análisis fitoquímico del extracto acuoso de C. ficifolia}

Debido a que al extracto acuoso de C. ficifolia se le ha atribuido efecto hipoglucemiante, por su contenido de DQI. Se caracterizó con base en el contenido de esta molécula mediante cromatografía líquida de alta resolución (HPLC). Para ello se utilizó un módulo de separación Waters 2695 con un detector de índice de refracción Waters 2697. Para la detección de DQI se usó una columna LiChospher amino $\left(\mathrm{NH}_{2}\right) 5 \mu \mathrm{m}\left(4 \times 250 \mathrm{~mm}, 100 \mathrm{~A}^{\circ}\right)$. La fase móvil consistió en una mezcla de acetonitrilo $\left(\mathrm{CH}_{3} \mathrm{CN}\right)$ y $\mathrm{H}_{2} \mathrm{O}$ en una proporción 90: 10, con un flujo de $1 \mathrm{ml} /$ minutos durante 10 minutos. La curva estándar se preparó con 4 concentraciones ascendentes $(50,100,200$ y $400 \mathrm{mg} / \mathrm{ml})$. El estándar de DQI de Sigma (Aldrich) fue inyectado con el mismo sistema de HPLC (GarcíaGonzález, 2011). 


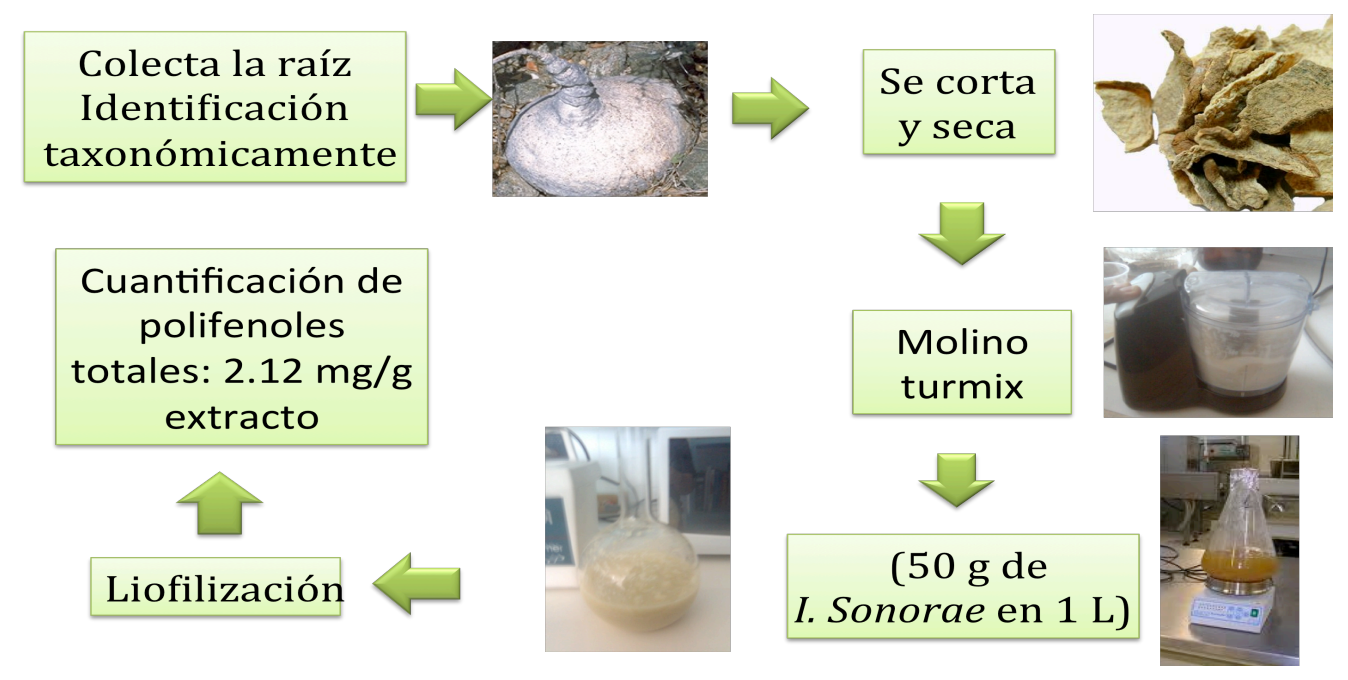

Figura 3. Obtención del extracto acuoso de I. sonorae.

\subsection{Cuantificación de polifenoles totales en el extracto acuoso de I. sonorae}

El contenido de polifenoles totales se realizó por el ensayo de Folin-Ciocalteau, descrito por Ghiselli (1998), el cual se basa en la oxidación de los fenoles por un reactivo de molibdeno y wolframio (tungsteno). Se tomó una alícuota de 5 y $50 \mu \mathrm{l}$ del extracto, el cual fue diluido en $2 \mathrm{ml}$ de agua desionizada $\left(\mathrm{H}_{2} \mathrm{Odd}\right)$ y se le adicionó $160 \mu \mathrm{l}$ el reactivo Folin (1:20) y $480 \mu \mathrm{l}$ carbonato de sodio al $20 \%$. Se incubaron durante 1 hora en oscuridad y temperatura ambiente y al término de este lapso se paró la reacción con $\mathrm{H}_{2} \mathrm{Odd}$ hasta obtener un volumen final de $4 \mathrm{ml}$. La cuantificación se realizó con una curva patrón de ácido gálico en un rango de 2-14 mg/L. Posteriormente la absorbencia fue medida a $760 \mathrm{~nm}$ (Pedret y col., 2012; H y col., 2012). 


\subsection{Efecto hipoglucémico del extracto acuoso de Cucurbita ficifolia Bouché e Ibervillea sonorae Greene}

Para evaluar el efecto hipoglucémico de los extractos acuosos de C. ficifolia e I. sonorae se realizó un estudio agudo en ratones sanos de la cepa mus musculus CD1 machos, de 8 semanas de nacimiento, con un peso promedio de $35 \mathrm{~g}$. Se midió la glucemia (Accu-Check sensor confort, Roche) en 3 grupos de ratones, a diferentes tiempos ( $n=6$, en cada grupo). La glucemia se midió al inicio $(t=0)$ en ratones con 12 horas de ayuno. Posteriormente se administraron los tratamientos por vía intragástrica de la siguiente manera: al grupo control se le administró solución salina; a los grupos control positivo se les administró glibenclamida 0.6 $\mathrm{mg} / \mathrm{Kg}$ (como control positivo del efecto hipoglucémico) o sitagliptina $1.43 \mathrm{mg} / \mathrm{Kg}$ (como control positivo del efecto hipoglucémico); los dos grupos restantes recibieron cada uno de los extractos $(500 \mathrm{mg} / \mathrm{Kg}$ para $\mathrm{l}$. sonorae y $200 \mathrm{mg} / \mathrm{Kg}$ para C. ficifolia) por separado. La glucemia se determinó a los 120, 240 y 360 minutos.

\subsection{Cultivo de la línea celular RINm5F}

La línea celular RINm5F es productora de insulina, proveniente de islotes pancreáticos tumorales (Tiedge y col., 1993). Se adquirió comercialmente de American Type Culture Collection (ATCC). Se sembraron en medio RPMI 1640 (11.1 mM de glucosa) (GIBCO). Fue suplementado con $10 \%$ de suero fetal bovino, $2 \mathrm{mM}$ L-glutamina, $1 \mathrm{mM}$ piruvato sódico, $20 \mu \mathrm{g} / \mathrm{L}$ de gentamicina, a $37^{\circ} \mathrm{C}$ con una atmósfera del $5 \%$ de $\mathrm{CO}_{2}$ y $95 \%$ de humedad hasta llegar a confluencia (aproximadamente 72 h). Para resembrarlas se utilizó tripsina $0.025 \%$ en PBS y 
se crecieron en placas de cultivo de 6 pozos; se llevaron a confluencia para iniciar los tratamientos.

El tratamiento con los extractos de C. ficifolia e I. sonorae se realizó a concentraciones de $0.25 \mu \mathrm{M}$ de DQI contenido en el extracto acuoso de $C$. ficifolia. De $0.25 \mu \mathrm{g} / \mathrm{ml}$ de extracto acuoso de $I$. sonorae equivalente a $5.75 \times 10^{-7}$ de polifenoles totales. A las 24 horas se recuperó el medio de cultivo y se les extrajo el RNA total. La concentración de insulina se determinó al inicio del cultivo y al final del tratamiento con el extracto correspondiente en las células de RINm5F, por el método de ELISA (ALPCO immunoassays) (Piro y col., 2002).

\subsection{Viabilidad celular (Prueba de MTT)}

Para determinar la viabilidad celular se utilizó la prueba de MTT por el método de Mosmann (1983), que se basa en la capacidad de las deshidrogenasas de la célula para reducir el bromuro de 3-(4,5-dimetiltiazol-2yl)-2,5-difenil tetrazolium (MTT) soluble en agua (amarillo), a formazán (azul) insoluble en agua. Se sembraron 5000 células/pozo en placa de 96 pozos (Nunc) con medio RPMI-1640 completo y se dejaron crecer por 24 horas a $37^{\circ} \mathrm{C}$. Después se lavaron con solución salina amortiguadora de fosfatos (PBS) y se les cambió el medio por uno sin suero fetal de bovino. Se realizó una curva de concentraciones. Las células se trataron con el extracto acuoso de C. ficifolia en concentraciones que van desde

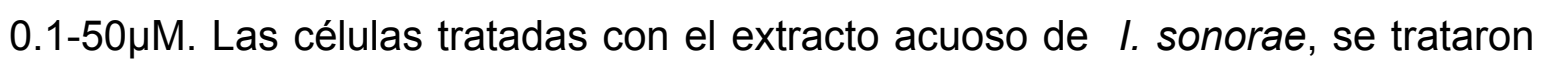
con concentraciones que van desde $0.1-10000 \mu \mathrm{g} / \mathrm{ml}$, durante 24 horas. Posteriormente a las células fueron lavadas con PBS y se les adicionó una solución de $0.1 \mathrm{mg} / \mathrm{ml}$ de MTT en PBS a pH 7.5. Se incubaron por 3 horas a 37 
${ }^{\circ} \mathrm{C}$ y $95 \%$ de humedad. Al finalizar el tiempo de incubación se retiró el medio (color amarillo) de las células y se les agregó $200 \mu$ de una solución de $\mathrm{HCl} 0.04$ M en 2-isopropanol, durante 15 minutos, para disolver el formazán. El cambio de absorbancia se leyó a $570 \mathrm{~nm}$ en un lector de ELISA. La funcionalidad se determinó por el porcentaje del cambio de extinción del MTT con respecto al grupo control (Mosmann., 1983; Stockert y col., 2012).

\subsection{Extracción de RNA total}

Para la extracción del RNA total de las células RINm5F se empleó la técnica descrita por Chomczynski (1993). Para cuantificar la expresión del gen de insulina se sembraron $1 \times 10^{6}$ células por cada tratamiento. Se trató a las células con el extracto acuoso de C. ficifolia y con DQI a una concentración de $0.25 \mu \mathrm{M}$. Para los tratamientos con el extracto acuoso de I. sonorae se utilizó una concentración de $0.25 \mu \mathrm{g} / \mathrm{ml}$, todos los tratamientos se aplicaron durante 24 horas. Posteriormente se colectó el medio de cultivo y fueron lavadas con PBS. Se agregó $1 \mathrm{ml}$ de Trizol $^{\circledR}$ y se levantaron con un gendarme de goma estéril. El homogenado se depositó en tubos Ependorff en donde se les dejó reposar 5 minutos a temperatura ambiente. Después se agregaron $0.2 \mathrm{ml}$ de cloroformo y se agitó el tubo por 15 segundos. Las muestras se centrifugaron a $11700 \mathrm{~g}$ durante 15 minutos a $4{ }^{\circ} \mathrm{C}$. Se colectó la fase acuosa (superior) y se le agregó $0.5 \mathrm{ml}$ de isopropanol; se dejó reposar 15 minutos a temperatura ambiente. Posteriormente se centrifugó a $11700 \mathrm{~g}$ durante 10 minutos a $4{ }^{\circ} \mathrm{C}$. Se decantó el sobrenadante y el precipitado obtenido se lavó con $1 \mathrm{ml}$ de etanol al $75 \%$ y se centrifugó a $11700 \mathrm{~g}$ durante 15 minutos a $4{ }^{\circ} \mathrm{C}$. Se desechó el sobrenadante y el precipitado (RNA 
total) obtenido se secó al vacío. El botón de RNA se suspendió en una solución de dietilpirocarbonato (DEPC) al $0.1 \%$ o agua libre de RNAasas. Se observó la integridad del ARN total, mediante un gel de agarosa al 1\% (Fig. 9). Finalmente se cuantificó el ARN por espectrofotometría mediante un NanoDrop ${ }^{\circledR}$ a una absorbencia de $260 \mathrm{~nm}$.

\subsection{Cuantificación de la expresión del ARNm de insulina}

Transcripción en Reversa acoplado a Reacción en Cadena de la Polimerasa (RTPCR) en tiempo real.

El cDNA se sintetizó a partir de $2 \mu \mathrm{g}$ de ARN total por PCR utilizando la transcriptasa reversa ImProm II, también se utilizaron iniciadores al azar (random primers $0.5 \mu \mathrm{g} / \mu \mathrm{l})$. El volumen total de reacción $(20 \mu \mathrm{g})$ se incubó en el termociclador de Applied Biosystems GeneAmp PCR System 2700 con el siguiente programa de ciclos: inicio $25^{\circ} \mathrm{C}$ por 5 minutos, seguido por la extensión a $42^{\circ} \mathrm{C}$ por 55 minutos y por último se detuvo la reacción inactivando la enzima a $70{ }^{\circ} \mathrm{C}$ por 15 minutos y enfriando a $4{ }^{\circ} \mathrm{C}$ por 5 minutos.

El cDNA se amplificó mediante la enzima ADN polimerasa del kit de "ADN master plus SYBR Green 1" para el gen a estudiar: insulina, y -actina como gen de normalización. El proceso se llevó a cabo empleando la tecnología SYBR Green con el equipo Rotor Gene. La mezcla de reacción con un volumen final de $10 \mu \mathrm{l}$ contuvo $0.5 \mathrm{mM}$ de oligonucleótidos de los genes insulina y Kir6.2, usando actina como gen de referencia (Tabla 1) y la mezcla de reacción 1X que contenía la enzima Fast Start, amortiguador para PCR, SYBR Green y $\mathrm{MgCl}_{2} 3.5 \mathrm{mM}$. 
Tabla 1. Secuencia de Primer y condiciones de PCR-RT

\begin{tabular}{|r|r|r|r|r|}
\hline Primer & Secuencia (sentido/antisentido) & $\begin{array}{r}\text { Temp de } \\
\text { alineación } \\
\left.\mathbf{(}^{\circ} \mathbf{C}\right)\end{array}$ & Tamaño & Ciclos \\
\hline $\begin{array}{r}\text { Rata } \\
\text { insulina }\end{array}$ & $5^{\prime}$-TGCCCAGGCTTTTGTCAAAC-3' & 61 & $187 \mathrm{pb}$ & 30 \\
\hline $\begin{array}{r}\text { Rata } \\
\text { Kir6.2 }\end{array}$ & $5^{\prime}$-GTACAGATCATTGTGGGCGT-3 & 61 & $320 \mathrm{pb}$ & 35 \\
\hline $\begin{array}{r}\text { Rata } \boldsymbol{\beta}- \\
\text { actina }\end{array}$ & 5'-GTGGGTATGGGTCAGAAGGA-3' & 61 & $380 \mathrm{pb}$ & 35 \\
\hline
\end{tabular}

\subsection{Cuantificación de $\mathrm{Ca}^{2+}$ intracelular}

Para determinar el contenido de $\mathrm{Ca}^{2+}$ intracelular se utilizó el método de Bellomo y col., 1982), el cual se basa en la medición espectrofotométrica del complejo formado por Arsenazo III (ácido 2, 2' dibencenoarsónico) y el $\mathrm{Ca}^{2+}$ libre intracelular. Se tomaron $5 \mu \mathrm{l}$ de fracción citosólica a la cual se le adicionó $1 \mathrm{ml}$ del indicador Arsenazo III $(30 \mu \mathrm{l})$ preparado en HEPES $5.0 \mathrm{mM}$ a pH 7.4. El complejo formado Arsenazo III-Ca ${ }^{2+}$ se leyó a una longitud de onda de 675 y 685 nm. La concentración intracelular de $\mathrm{Ca}^{2+}$ se determinó utilizando la siguiente ecuación: $\mathrm{C}=\Delta \mathrm{Abs} /\left(-{ }^{\prime}\right) \mathrm{I}$

Donde: 
C: es la concentración de $\mathrm{Ca}^{2+}$ intracelular, $\triangle \mathrm{Abs} 675-685$, es el coeficiente de extinción molar $\left(2.80 \times 10^{4} / \mathrm{cmM}\right)$ del complejo Arsenazo III-Ca ${ }^{2+}$, es el coeficiente de extinción molar $\left(0.19 \times 10^{-4} / \mathrm{cmM}\right)$ del Arzenazo III libre de calcio y 1 es el grosor de la celda. Los resultados se expresan como mol de calcio libre intracelular/mg de proteína.

\subsection{Determinación del Contenido de Proteína}

El contenido de proteína en las muestras se realizó por el método de Bradford (1976) con el reactivo de Bradford (Bio-Rad). Se tomó una alícuota de $5 \mu$ le las muestras y se le agregó $2.5 \mathrm{ml}$ del reactivo Bradford (1:4), se incubó 20 minutos a $25^{\circ} \mathrm{C}$. La cuantificación fue realizada con una curva patrón de albúmina sérica bovina en un rango de 0.1-0.5 mg/ml. Posteriormente se leyó la absorbencia y se determinó la concentración de la proteína.

\subsection{Cuantificación de la secreción de insulina por el método de ELISA}

Para cuantificar la secreción de insulina se usó la técnica de ELISA. Se basa en un inmunoensayo tipo sandwich con anticuerpos monoclonales específicos para insulina, inmobilizados en una microplaca de 96 pozos en una fase sólida que contiene controles estándares. Se colectó el medio RPMI de las células tratadas durante 24 horas. Cada uno de los extractos correspondientes se añadió a los pozos apropiados con una enzima peroxidasa de rábano y un anticuerpo monoclonal marcado (conjugado). Las moléculas de insulina queden intercaladas entre la fase sólida y el conjugado. Después de incubar por 2 horas en un agitador mecánico a temperatura ambiente, los pozos de la microplaca se lavaron con buffer de lavado para eliminar el conjugado no unido. Posteriormente se adicionó 
a cada pozo el sustrato proporcionado por el proveedor, incubando nuevamente la microplaca en un agitador mecánico a temperatura ambiente por 15 minutos. Durante este tiempo el sustrato reacciona con el conjugado unido en los pozos. Después del tiempo de incubación se detuvo la reacción, añadiendo "stop solution", cambiando el color de azul a amarillo. Finalmente se midió la densidad óptica por lector de microplacas a $450 \mathrm{~nm}$ con una longitud de onda de referencia de $620 \mathrm{~nm}$. La intensidad del color generado es directamente proporcional a la cantidad de insulina en la muestra.

\subsection{Análisis estadístico}

Cada experimento se realizó por triplicado en eventos independientes. El análisis estadístico de los resultados obtenidos se realizó mediante un análisis de varianza (ANOVA) seguido por la prueba de Tukey-Kramer. Se utilizó un nivel de significancia del 95\%.

\section{Resultados}

\subsection{Cultivo de las células RINm5F}

Transcurridas 96 horas se observa el crecimiento de las células en monocapa y en confluencia (Fig. 4). 

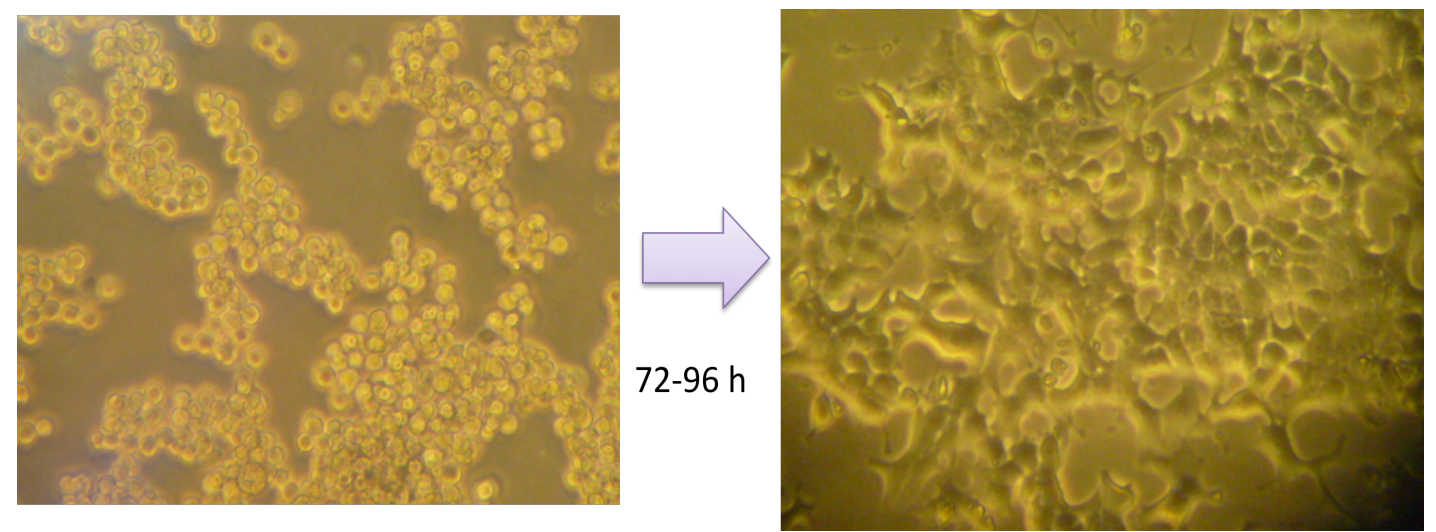

Figura 4. Establecimiento de la línea celular RINm5F en medio RPMI 1640 suplementado con SFB 10\%.

7.2 Cuantificación de DQI y de polifenoles totales en el extracto acuso de C. ficifolia e I. sonorae, respectivamente.

En la caracterización química por HPLC del extracto acuso de C. ficifolia se encontró que hay $3.32 \mathrm{mg}$ de DQI por gramo de extracto de C. ficifolia.

Se obtuvieron $5 \mathrm{~g}$ de la raíz de $\mathrm{I}$. Sonorae, con un rendimiento del 10\% (Figura 3). Además se encontró que tiene $2.3 \mathrm{mg}$ de polifenoles totales por gramo de extracto de I. sonorae.

\subsection{Efecto hipoglucémico del extracto acuoso de C. ficifolia}

El grupo al que se les administró sitagliptina (como control positivo del efecto hipoglucémico), se observa una disminución de la glucosa del $75 \%$ al minuto 120 . La glucemia del grupo de ratones a los que se les administró el extracto acuoso de C. ficifolia mostró un descenso de $75 \%$ al minuto 240 , en comparación con el grupo control. Sin embargo, el efecto hipoglucémico del extracto acuoso de $C$. ficifolia, se mantuvo hasta el minuto 360 del estudio (Fig. 5). 


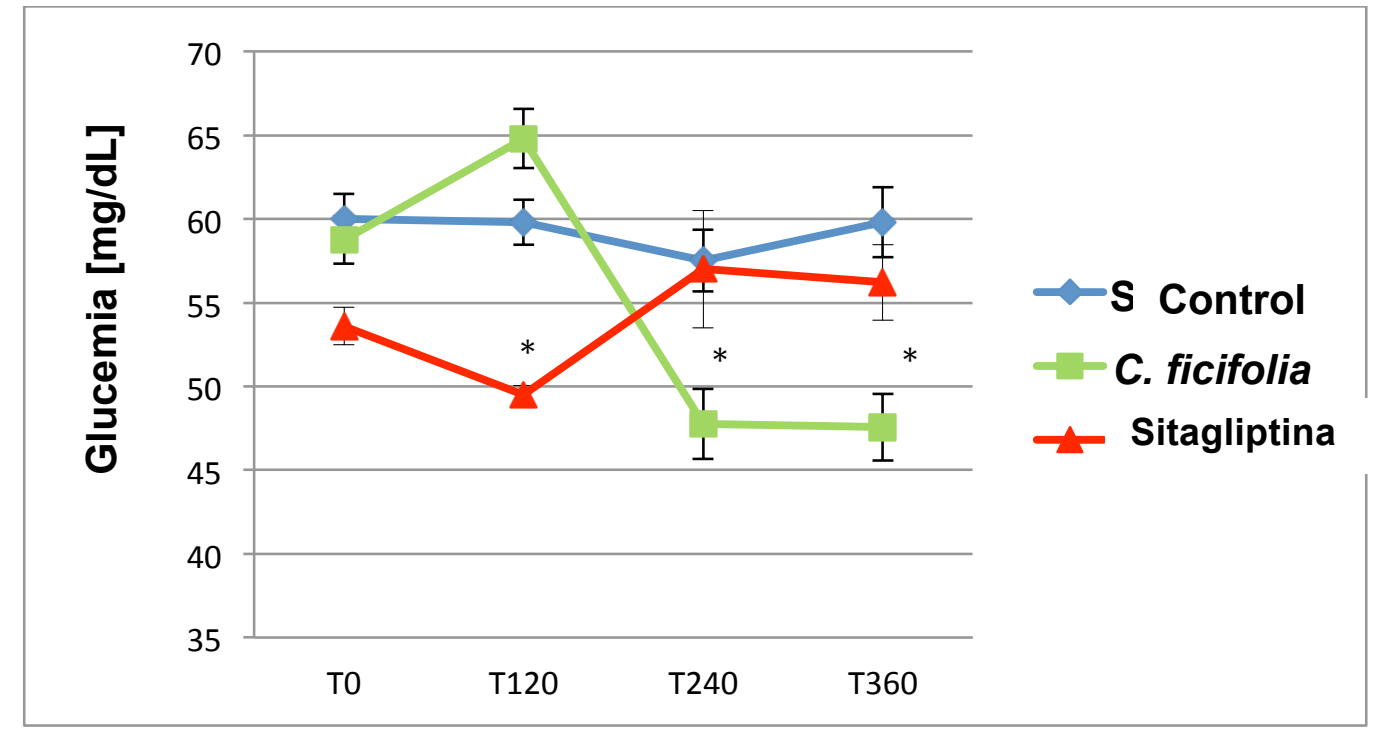

Tiempo en minutos

Figura 5. Glucemias después de la administración de C. ficifolia, sitagliptina y solución salina. (* Diferencia significativa respecto al grupo control, $p<0.05$ ). Media \pm S.M.E $(n=6)$.

\subsection{Efecto hipoglucémico del extracto acuoso de $I$. sonorae}

El grupo al que se le administró glibenclamida (como control positivo del efecto hipoglucémico) mostró descenso del $25 \%$ al minuto 120 , en comparación con el grupo control. El grupo de ratones a los que se les administró el extracto acuoso de $I$. sonorae mostró un descenso del $75 \%$ de glucosa en sangre, al minuto 240 , estadísticamente significativo en comparación con el grupo control. Debido a la hipoglucemia generada, únicamente sobrevivieron 4 ratones. Demostrándose así el efecto hipoglucemiante del extracto acuoso de I. sonorae (Fig. 6). 


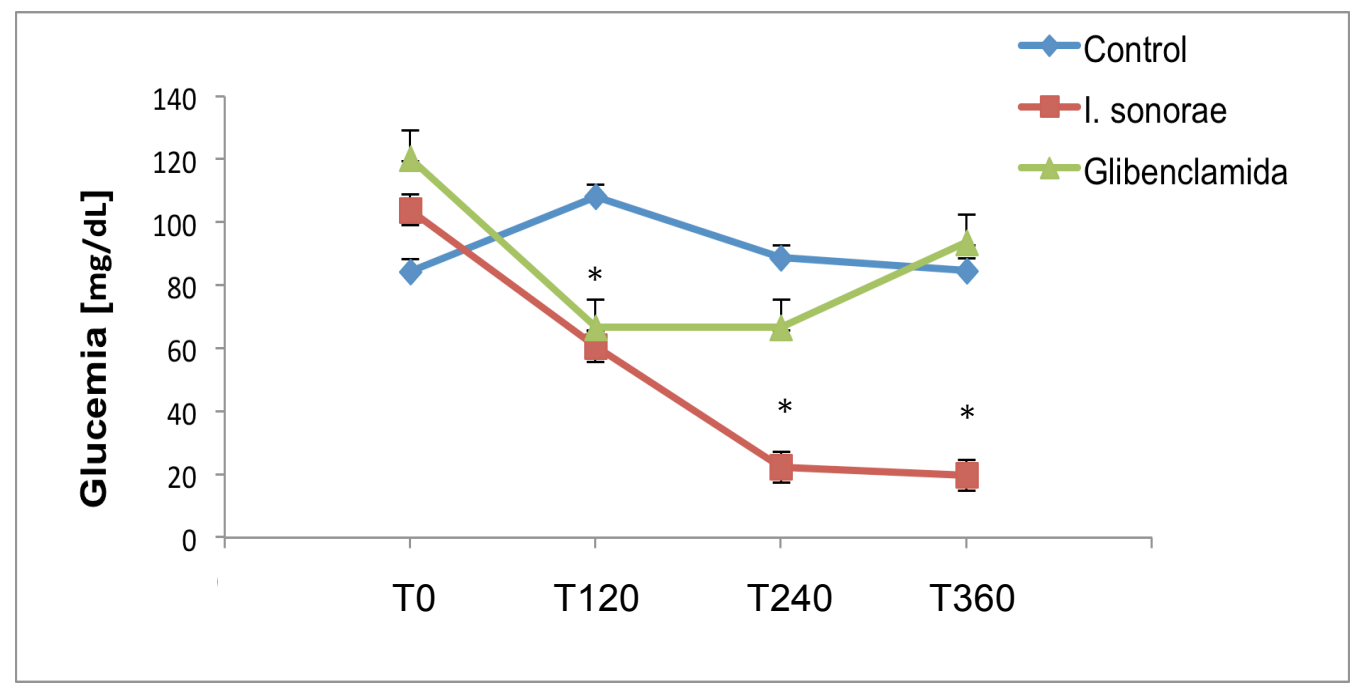

Tiempo en minutos

Figura 6. Glucemias después de la administración del extracto acuoso de $I$. sonorae, glibenclamida y solución salina. ( ${ }^{*}$ Diferencia significativa respecto al grupo control, $p<0.05)$. Media \pm S.M.E $(n=6)$.

\subsection{Prueba de MTT en las células RINm5F}

Las células RINm5F tratadas con el extracto acuoso de C. ficifolia y DQI a la concentración de 0.25 M mostraron un $98 \%$ de funcionalidad de las deshidrogenasas de la célula, en comparación con el grupo control (100\%). A partir de $1 \mu \mathrm{M}$ se observa una disminución del $20 \%$ en la funcionalidad de las deshidrogenasas, estadísticamente significativo, en comparación con el grupo control. Mostrando un efecto citotóxico del extracto acuoso de C. ficifolia concentración-dependiente. Por lo que la concentración de $0.25 \mu \mathrm{M}$ fue la elegida 
para tratar a las células, tanto con el extracto acuoso de C. ficifolia como con DQI (Figura 7).

La funcionalidad de las células RINm5F se midió a diferentes concentraciones del extracto acuoso de I. sonorae con la prueba de MTT. Las células tratadas con $0.25 \mu \mathrm{g} / \mathrm{ml}$ (equivalente a $5.75 \times 10^{-7} \mathrm{mg}$ de polifenoles) del extracto acuoso de $I$. sonorae mostraron un $105 \%$ de funcionalidad en comparación con el grupo control (100\%). A partir de la concentración de $1 \mu \mathrm{g} / \mathrm{ml}$ de este extracto, se observa disminución del $20 \%$ de funcionalidad estadísticamente significativo, en comparación con el grupo control. Mostrando un efecto tóxico del extracto acuoso de I. sonorae concentración-dependiente. Por lo que la concentración de $0.25 \mu \mathrm{g} / \mathrm{ml}$ fue la elegida para tratar a las células (Fig. 8).

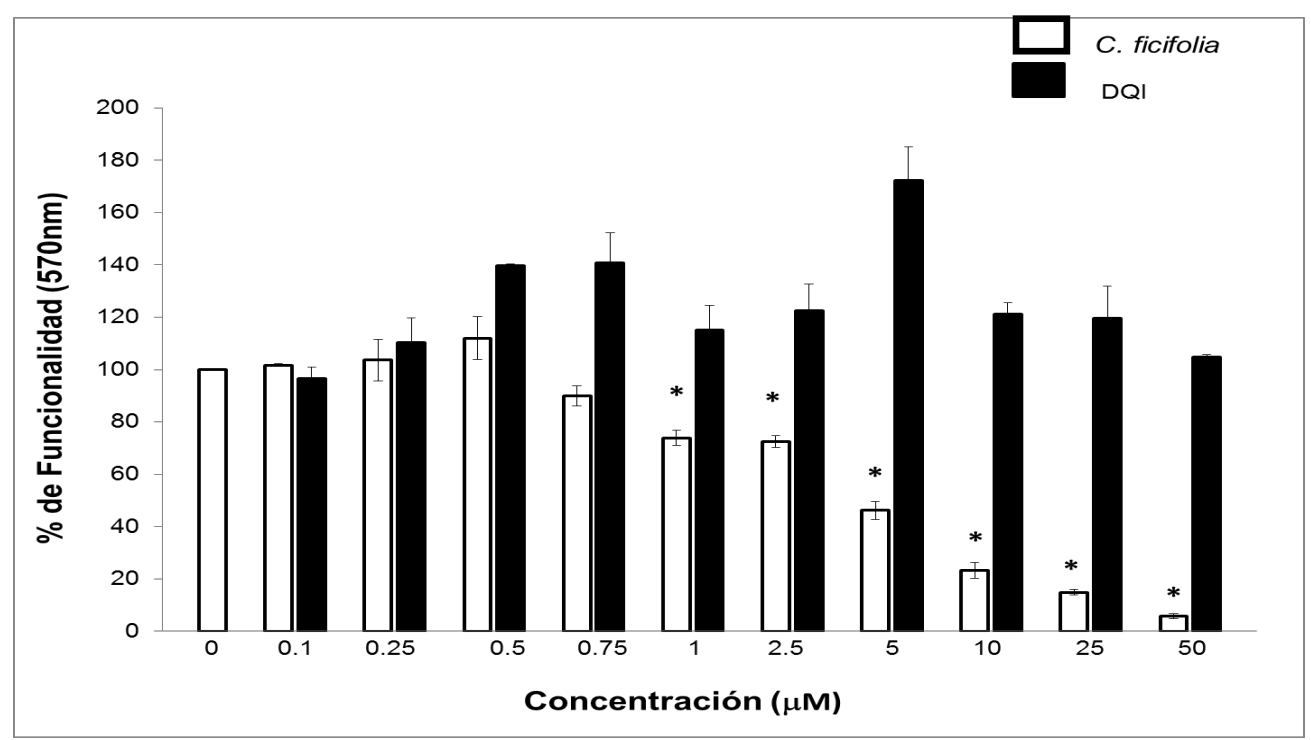

Figura 7. Efecto del tratamiento con el extracto acuoso de C. ficifolia sobre la funcionalidad de las deshidrogenasas de las células RINm5F. Las células tratadas con concentraciones de $0.1-50 \mu \mathrm{M}$ durante 24 horas. El \% de funcionalidad de las 
deshidrogenasas de las células se analizó mediante la prueba de MTT. (* Diferencia significativa respecto al grupo control, $p<0.05)$. Media \pm S.M.E $(n=6)$.

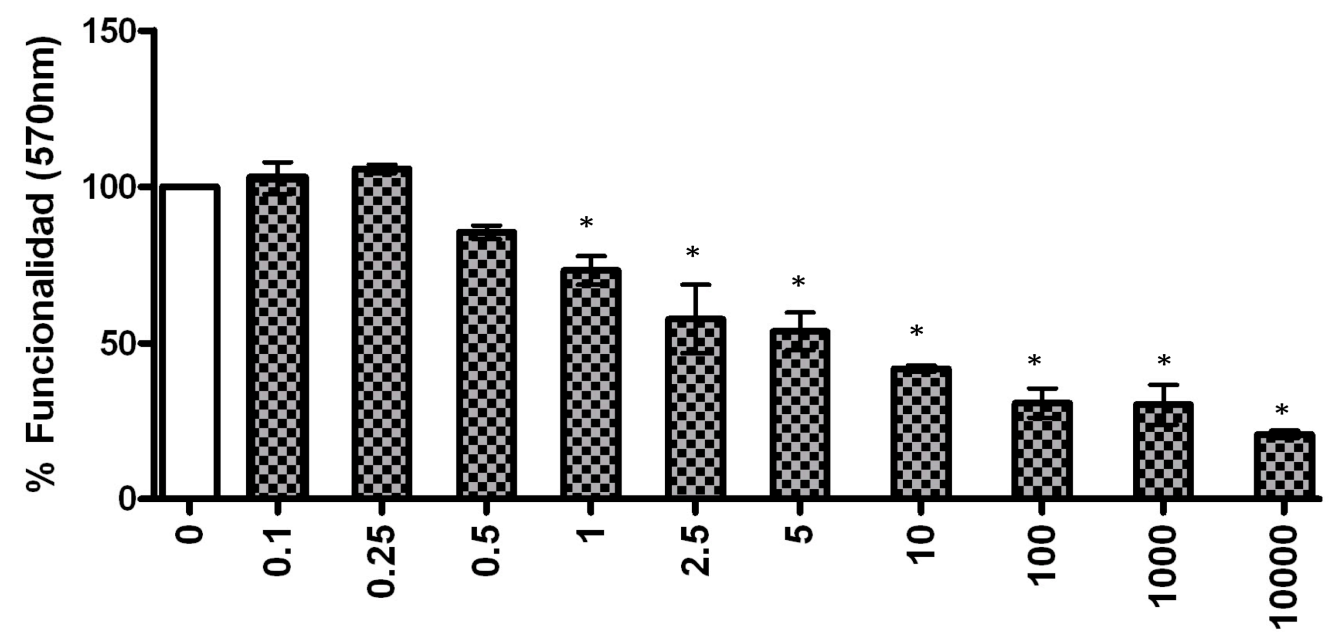

$\mu \mathrm{g} / \mathrm{mL}$

Figura 8. Efecto del tratamiento con el extracto acuoso de I. sonorae sobre la funcionalidad de las deshidrogenasas de las células RINm5F. Las Células tratadas con concentraciones de 0.1-10000 $\mu$ g durante 24 horas. El \% de funcionalidad se analizó mediante la prueba de MTT. ( ${ }^{*}$ Diferencia significativa respecto al grupo control, $p<0.05)$. Media \pm S.M.E $(n=6)$.

\subsection{PCR en tiempo real para las células RINm5F}

En la Figura 9 se representa en el eje $\mathrm{Y}$ la fluorescencia emitida. A mayor fluorescencia, mayor expresión de los genes que se cuantificaron (insulina y Kir 6.2). El eje $\mathrm{X}$ representa el número de ciclos (Ct) a los que se amplificó el gen. Se utilizó el gen constitutivo actina como gen de referencia. 


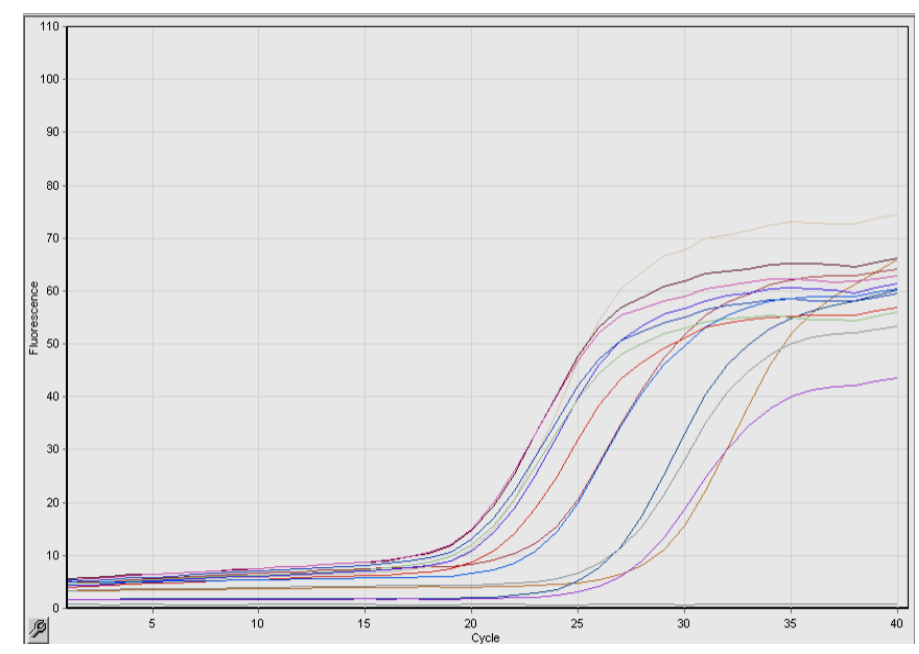

Figura 9. Curvas de amplificación de PCR en tiempo real para el gen de insulina y Kir 6.2. El cDNA fue sintetizado con $2 \mu \mathrm{g}$ total de ARN por PCR transcriptasa reversa. Kit "DNA master plus SYBR Green 1 PCRMasterMix.

\subsection{Expresión del gen de insulina de las células RINm5F}

Las células tratadas con el extracto acuoso de C. ficifolia y DQI mostraron mayor expresión del gen de insulina (6 y 4 veces más, respectivamente), estadísticamente significativa en comparación con el grupo control. Las células tratadas con glibenclamida no mostraron diferencia significativa en comparación con el grupo control (Fig. 10A). Por su parte, las células tratadas con el extracto acuoso de $I$. sonorae mostraron menor expresión del gen de insulina (20\%), estadísticamente significativa en comparación con el grupo control. Las células tratadas con glibenclamida no mostraron diferencia estadísticamente significativa (Fig. 10B). 
A

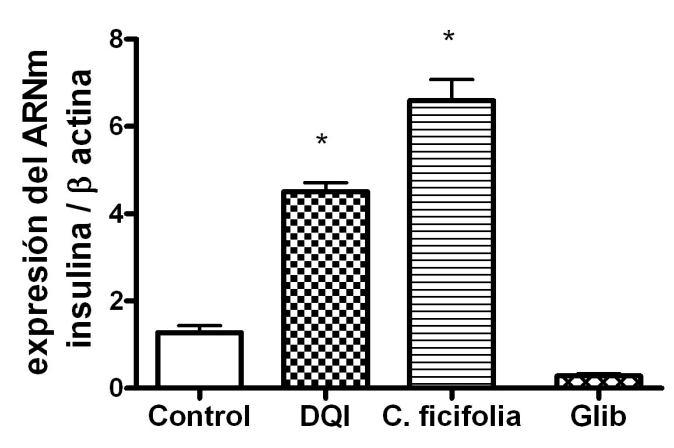

B

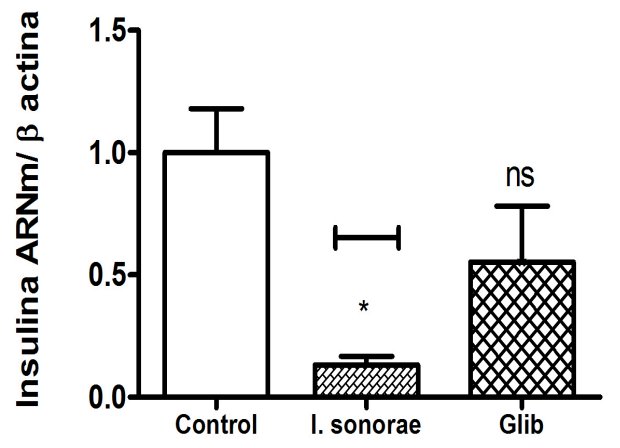

Figura 10. A: expresión del gen de insulina en células tratadas con el extracto acuoso de C. ficifolia y DQI. B: expresión de insulina de las células tratadas con el extracto acuoso de I. sonorae. (" Diferencia significativa respecto al grupo control, $p<0.05)$. Media \pm S.M.E analizados con la prueba ANOVA $(n=6)$. Glib: Glibenclamida, ns: diferencias no significativas en comparación con los grupos I. sonorae y Glib; Glib y grupo control).

\subsection{Expresión del gen Kir 6.2 de las células RINm5F}

Las células tratadas con $0.25 \mu \mathrm{M}$ del extracto acuoso de C. ficifolia y DQI incrementaron 150 veces la expresión del gen Kir6.2, estadísticamente significativa en comparación con el grupo control. Las células tratadas con $4 \mu \mathrm{M}$ de glibenclamida, no mostraron diferencia estadísticamente significativa con respecto al control (Fig. 11A). Las células tratadas con $0.25 \mu \mathrm{g} / \mathrm{ml}$ del extracto acuoso de $I$. sonorae, no mostraron diferencias estadísticamente significativas en la expresión del gen Kir 6.2, en comparación con el grupo control (Fig. 11B). 

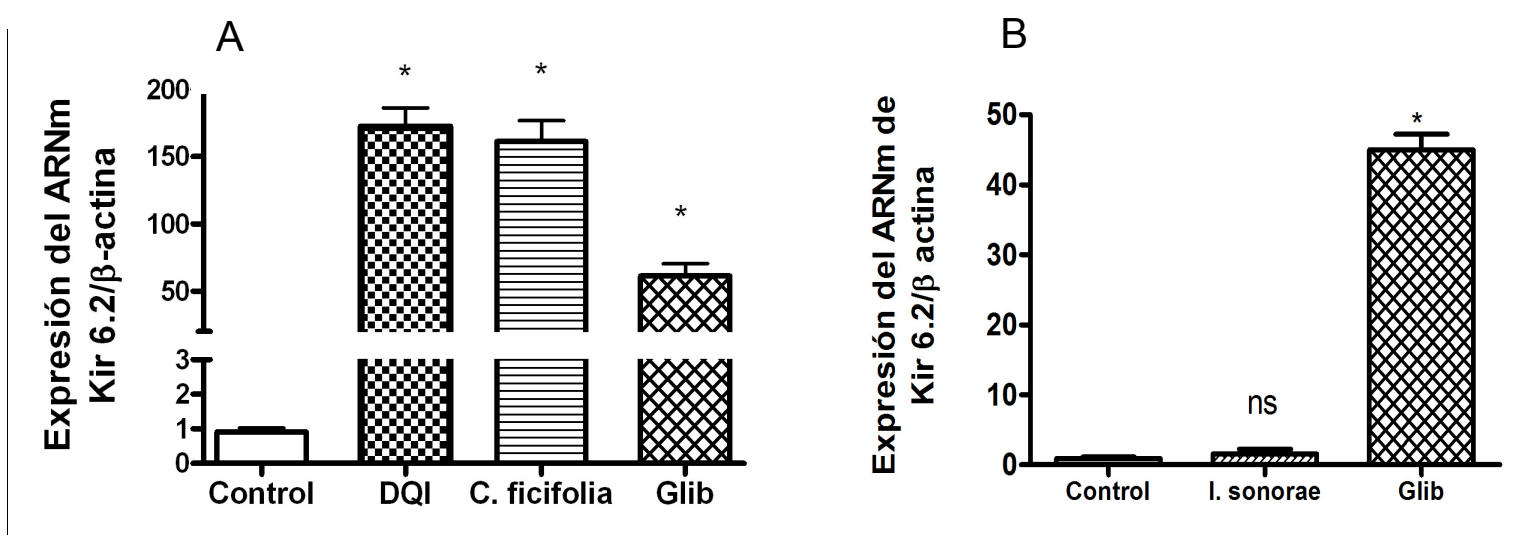

Figura 11. Expresión de Kir 6.2 de las células tratadas con el extracto acuso de C. ficifolia y DQI (A) (ns: diferencias no significativas en comparación con el grupo DQI y el extracto acuso de C. ficifolia). Así como con el extracto acuoso de $I$. sonorae (B). ( ${ }^{*}$ Diferencia significativa respecto al grupo control, $\left.p<0.05\right)$. Media \pm S.M.E analizados con la prueba ANOVA $(n=6)$. Glib: Glibenclamida, ns: diferencias no significativas en comparación con el grupo control.

\section{9 $\mathrm{Ca}^{2+}$ intracelular de las células RINm5F}

La concentración de $\mathrm{Ca}^{2+}$ intracelular en las células tratadas con $0.25 \mu \mathrm{M}$ del extracto acuoso de C.ficifolia, DQI y glibenclamida $(4 \mu \mathrm{M})$ aumentó $(160 \%, 180 \%$ y $200 \%$, respectivamente) de manera estadísticamente significativa en comparación con el grupo control (Fig. 12A). Las células tratadas con $0.25 \mu \mathrm{g} / \mathrm{ml}$ del extracto acuoso de I. sonorae muestran un incremento del $80 \%$ en la concentración de $\mathrm{Ca}^{2+}$ intracelular, estadísticamente significativa en comparación con el grupo control (Fig. 12B). 
A

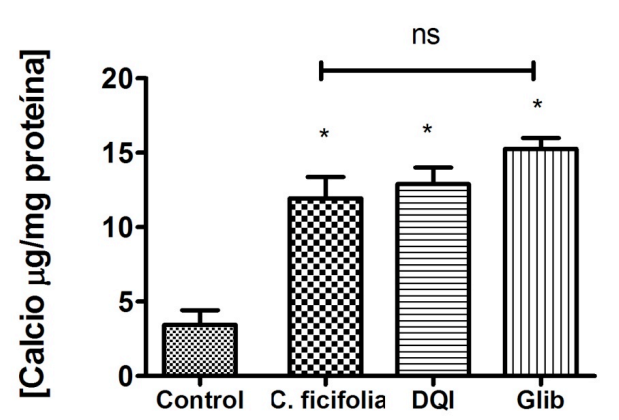

B

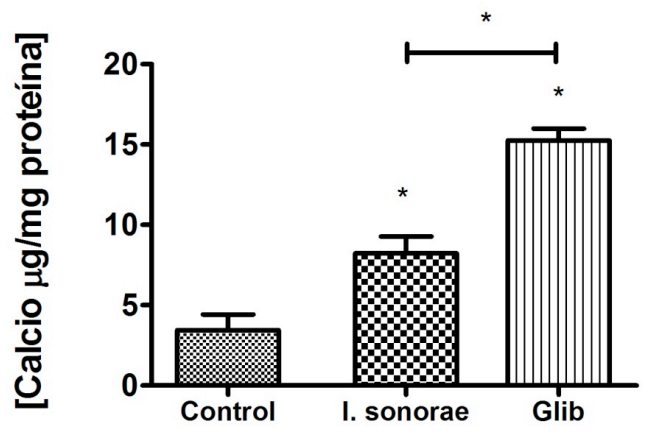

Figura 12. A: Concentración de $\mathrm{Ca}^{2+}$ intracelular en las células tratadas con el extracto acuoso de C. ficifolia, DQI y Glib. B: células tratadas con el extracto acuoso de I. sonorae. ( ${ }^{*}$ Diferencia significativa respecto al grupo control, $p<$ 0.05). Media \pm S.M.E analizados con la prueba ANOVA $(n=6)$. Glib: glibenclamida.

\subsection{Secreción de insulina de las células RINm5F}

Las células tratadas con el extracto acuoso de C. ficifolia, DQI y glibenclamida muestra mayor secreción de insulina $(11 \%, 5 \%$ y 17\%, respectivamente), estadísticamente significativa, en comparación con el grupo control. Las células tratadas con glibenclamida muestran mayor secreción de insulina $(21 \%)$ en comparación con el grupo tratado con C. ficifolia (Fig. 13A).

La secreción de insulina en las células tratadas con el extracto acuoso de $I$. sonorae, así como las células tratadas con glibenclamida muestra mayor secreción de insulina (35\%, en ambos tratamientos), estadísticamente significativa, en comparación con el grupo control (Fig. 13B). 
A

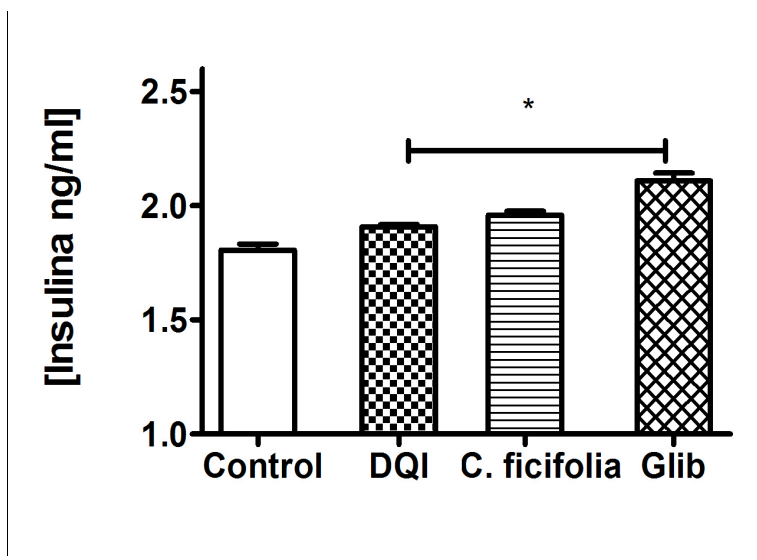

B

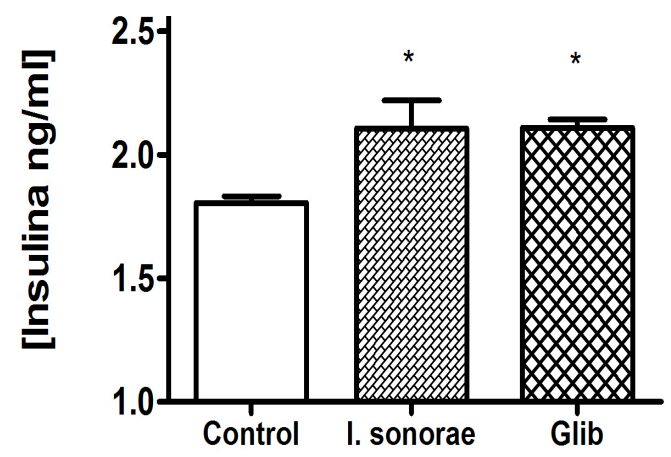

Figura 13. Secreción de insulina en células tratadas con el extracto acuoso de C. ficifolia, DQI y Glib (A). Así como de las células tratadas con el extracto acuoso de I. sonorae (B). ( ${ }^{*}$ Diferencia significativa respecto al grupo control, $\left.p<0.05\right)$. Media \pm S.M.E analizados con la prueba ANOVA $(n=6)$. Glib: glibenclamida, ns: diferencia estadísticamente no significativa entre los grupos $C$. ficifolia y $D Q,{ }^{* *}$ Significativamente diferente entre el grupo tratado con C. ficifolia y Glib. 


\section{DISCUSIÓN}

Cucurbita ficifolia (popularmente conocida como chilacayote) es una planta comestible mexicana cuya actividad hipoglucemiante, antioxidante y antiinflamatoria han sido demostradas en varias condiciones experimentales y clínicas (Roman-Ramos y col., 2012). Este estudio es una aproximación a la elucidación del efecto hipoclucémico de C. ficifolia por aumento en la expresión del gen de insulina y del gen que codifica para la proteína que constituye el canal

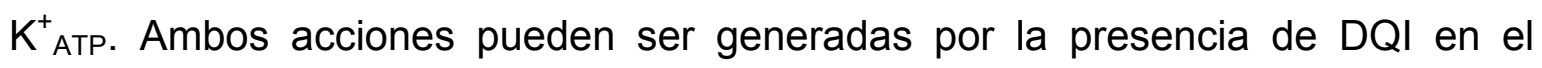
extracto.

Recientemente el DQI se propuso como el compuesto responsable de los efectos hipoglucemiantes de los frutos de C. ficifolia (Xia y col., 2006). DQI fue originalmente descubierto como un mediador de la acción intracelular de la insulina. Se ha demostrado que acelera la defosforilación de las enzimas, glucógeno sintasa y piruvato deshidrogenasa. Lo que limita las enzimas de la eliminación de la glucosa en la vías oxidativa y no oxidativa (Roman-Ramos y col., 2012). Algunos estudios demostraron la existencia de una relación lineal entre la disminución de la excreción urinaria de la glucosa y el grado de resistencia a la insulina (Laner, 2001). Cuando se analizó el contenido de los tejidos, incluyendo los músculos de los sujetos con diabetes tipo 2 , se demostró una deficiencia corporal más general de DQI. La administración de DQI en ratas diabéticas, monos rhesus y humanos aceleró la utilización de glucosa y la acción de la insulina (Xia y col., 2006). Se observó aumento significativo en la expresión del gen de insulina y la secreción de insulina de las células RINm5F tratadas con DQI. Este resultado apoya la idea de que esta molécula es en parte, responsable 
del efecto hipoglucémico del extracto acuoso de C. ficifolia. Sin descartar la idea, de que el sinergismo de otras moléculas contenidas en este extracto, estén realizando su efecto hipoglucémico.

Por otro lado, Ibervillea sonorae Grenne (popularmente conocida como "wareque") es una planta dioica perenne. Entre las plantas más utilizadas para el control de la diabetes mellitus se encuentra $I$. sonorae. Sin embargo, se desconocen sus principios activos y los mecanismos de acción hipoglucemiante. Aspecto primordial para poder fundamentar y validar científicamente su uso en pacientes (Alarcón y col., 2005).

En estudios preliminares se ha logrado observar que los tubérculos de $I$. sonorae colectados en diferentes épocas del año, pueden diferir en cuanto a su actividad biológica (Alarcón y col., 2008). Probablemente, su contenido de principios activos es diferente. Considerando que el fruto de C. ficifolia se colecto en el mes de septiembre y que se obtuvo un extracto a partir de éste, se decidió comprobar su efecto hipoglucémico.

El efecto hipoglucémico de C. ficifolia evaluado en este estudio, concuerda con la literatura (Alarcón y col., 2002; Andrade-Ceto y col., 2005; Xia y col., 2006). El efecto hipoglucémico del fruto de $C$. ficifolia se ha estudiado en diversos modelos como: ratas, ratones y conejos. Los estudios realizados con ratones sanos a los que se administraron $500 \mathrm{mg} / \mathrm{Kg}$ peso del jugo de C. ficifolia vía intraperitoneal y oral, demostraron su efecto hipoglucémico (disminución de hasta $50 \mathrm{mg} / \mathrm{dl}$ ). Este efecto también se observó en ratas con aloxana bajo un esquema de tratamiento que involucra la administración diaria (500 mg/Kg de peso), vía oral, del jugo de 
C. ficifolia durante 14 días (disminución de glucosa de manera progresiva; de hasta $50 \mathrm{mg} / \mathrm{dl}$ ) (Alarcón y col., 2002).

Los resultados con el extracto acuoso de I sonorae, también concuerdan con lo encontrado en la literatura. En un estudio in vivo se administró de manera aguda y crónica tanto la preparación tradicional (decocción acuosa) como el extracto crudo (jugo) de la raíz, dando como resultado reducciones significativas de la glucemia en ratones sanos tras la administración intraperitoneal $(600 \mathrm{mg} / \mathrm{kg}$ para ambos extractos). Así mismo, la dosis de $300 \mathrm{mg} / \mathrm{kg} / \mathrm{día}$ por vía oral a ratas diabéticas causó mejora significativa en el peso corporal, en la glucemia, en comparación con el grupo diabético que no recibió el extracto (Alarcón y col., 2005).

El extracto acuoso de C. ficifolia y el DQI aumentaron significativamente la expresión del ARNm de insulina, así como de la secreción de insulina (Figura 10A y $13 \mathrm{~A}$, respectivamente), estadísticamente significativa en comparación con el grupo control. Esto proporciona evidencia de la actividad del extracto acuoso de C. ficifolia y apoya su uso como un coadyuvante en el tratamiento de la diabetes.

Sin embargo, la secreción de insulina no sólo está regulada por glucosa, secretagogos no glucosídicos (aminoácidos y lípidos), hormonas insulinotropas y neurotransmisores (Montanya y col., 2007). Además por las acciones combinadas de factores de transcripción, que también son necesarios para el desarrollo y la supervivencia de las células de los islotes pancreáticos. Algunos de los factores más importantes que modulan la expresión del gen de insulina son: el factor de transcripción v-maf fibrosarcoma músculo-homólogo del oncogén A (MafA), el factor de transcripción pancreático/duodenal homeobox-1 ( $\mathrm{Pdx}-1)$ y el factor de 
diferenciación neurogénica 1 (NeuroD1) (Inada y col., 1999; Lee y col., 2000; Kaneto y col., 2002; Ren y col., 2007). (Palgi y col., 2000; Yang y col., 2009; Cho y col., 2012). Estos factores regulan la transcripción del gen de insulina en respuesta a diferentes estímulos, como lo son glucosa y la unión de GLP-1 a su receptor.

La fosforilación en PDX-1 y la glucosilación en MafA y NeuroD1 se requieren para su movilización al núcleo e induzcan expresión del gen de insulina. No hay evidencias de que el extracto acuso de $C$. ficifolia contenga moléculas con estructura química, similar, que active a estos factores. Sin embargo, se observó un incremento en la expresión del gen de insulina de las células RINm5F tratadas con este extracto.

Un estudio en la línea celular proveniente de insulinoma de ratón MIN6, mutantes para FOXA2 (por sus siglas en inglés: Forkhead box a2, formerly Hepatocyte nuclear factor 3beta), mostró una mayor secreción de los gránulos de insulina. Adicionalmente, en ese mismo estudio se demostró que la inactivación del gen FOXA2 en células maduras induce hiperinsulinismo e hipoglucemia en ratones adultos (Lantz y col., 2004). Además regula genes, que pueden controlar la biogénesis de los gránulos de insulina y las interacciones de las proteínas SNARE para su secreción (Gao y col., 2007). En otro estudio se encontró que las células que carecen de FOXA2 son esencialmente deficientes para las subunidades del

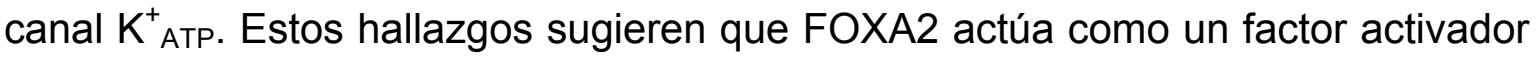
transcripcional de la subunidad SUR1, así como del canal Kir6.2 en las células . Al sobreexpresar FOXA2 resulta en la activación de casi 4 veces más a Kir6.2. FOXA2 es un potente transactivador de ambos genes en las células del 
páncreas (Lantz y col., 2004). Podemos sugerir que el extracto acuoso de $C$. ficifolia podría estar activando a factores de transcripción involucrados con la expresión de insulina y Kir 6.2, de tal manera que se incremente su expresión. Sin embargo, es necesario realizar más estudios. Por ejemplo, adicionar un inhibidor de la expresión del gen de insulina para confirmar si esta actividad es mediada por el extracto acuoso de C. ficifolia. También se observó mayor secreción de insulina $(11 \%)$ en las células RINm5F tratadas con el extracto acuoso de $C$. ficifolia. Este resultado concuerda con un estudio en el que se trató a ratones sanos con el extracto acuoso de C. ficifolia y se observó mayor secreción de insulina (11\%) con respecto al control diabético (García-González, 2011).

Por otro lado, hay factores que inhiben la expresión del gen de insulina. Tal es el caso de la exposición crónica de las células a concentraciones de glucosa superiores a las fisiológicas $(30 \mathrm{mM})$ debido a DT2. Lo que da lugar a la disminución de la transcripción del gen de insulina. El factor de transcripción CCAAT/potenciador de unión a la proteína beta (C/EBPbeta), (basic helix-loophelix transcription por sus siglas en inglés) es un represor de la transcripción del gen de insulina en condiciones de glucosa alta (Lu y col., 1997). Probablemente el efecto de I. sonorae de disminuir la expresión del gen de insulina sea activar estas moléculas, sin embargo no hay evidencias al respecto.

En las células ， la transcripción del gen Mct1 que codifica para la proteína MCT1 (transportadora de monocarboxilatos) tiene que ser muy bajo. Esto con el fin de evitar la liberación de insulina no apropiada desencadenada mediante la circulación de piruvato (Schuit y col., 2012). En una rara enfermedad genética, que conduce a una mutación en el promotor MCT1 induce que aumente en las 
células . Esto causa hipoglucemia por el hiperinsulinismo. Este ejemplo sugiere que otras proteínas también podría participar en la liberación anormal de insulina (Schuit y col., 2012). Quizá el extracto acuoso de I. sonorae actúa sobre alguno de estos mecanismos para reprimir la expresión del gen de insulina.

La línea celular RINm5F proviene de un insulinoma de rata (Palgi y col., 2000; Marsich y col., 2003; Matsuda y col., 2005). Los insulinomas son generalmente causados por tumores pequeños del páncreas y una de las principales características de esta enfermedad es la secreción excesiva de insulina (Lammoglia y col., 2008). El exceso en la transcripción del gen de insulina y la secreción de la misma son características de la línea celular.

Sin embargo, este estudio muestra que las células tratadas con el extracto acuoso de $I$. sonorae induce menor expresión del gen de insulina (Figura 10B). Se sugiere que debe actuar sobre el mecanismo de represión del gen de insulina. La única acción aparente es la de secretar la insulina preformada en las células RINm5F, probablemente debido a un aumento de la concentración intracelular de $\mathrm{Ca}^{2+}$ intracelular (Fig. 12B).

Las células tratadas con glibenclamida, un potente agente hipoglucemiante, perteneciente a la clase de las sulfonilureas, actúa a nivel del canal de $\mathrm{K}^{+}$ATP. Es uno de los principales fármacos disponibles para el tratamiento de la DT2. Los niveles de ARNm de insulina de las células tratadas con glibenclamida, no generó cambios significativos (Fig. 10A y 10B). A corto plazo, el mecanismo de acción de las sulfonilureas es liberan la insulina preformada en las células del páncreas. Su alta afinidad a la proteína SUR1 (constituyente de este canal) permite el cierre 
del canal de $\mathrm{K}^{+}{ }_{\text {ATP }}$ para aumentar la concentración del $\mathrm{Ca}^{2+}$ e inducir la secreción de insulina (Florez y col., 1997). Esto explica por qué la glibenclamida no induce la expresión del ARNm de la insulina. Su mecanismo de acción no es a través de aumento en la expresión de este gen. En este estudio, la glibenclamida estimula la expresión del gen Kir6.2 (Figura 11A y 11B). Sin embargo, hasta el momento no hay informes en relación con este hallazgo. La importancia de estimular la expresión del gen Kir6.2, radica en el papel que juega este canal en la secreción de la insulina.

Estos canales (Kir6.2-SUR1) determinan el potencial transmembrana en reposo porque se encuentran abiertos en situación de equilibrio. Son tetradímeros rectificadores de entrada rápidos (KIR6.x) que cuentan con receptores de sulfonilurea (SUR), miembros de la superfamilia ATP cassette vinculante (ABC) (Fatehi y col., 2012). Estos canales responden a eventos metabólicos para generar actividad eléctrica en la membrana plasmática. SUR1 se asocia a las subunidades KIR6.2 con estequiometria 4:4 para formar el canal tetramérico, (SUR1/KIR6.2). Las subunidades KIR6.2 forman el poro del canal, mientras que SUR1 se requiere para la activación y la regulación. Su cierre permite la actividad de otros canales, como lo es el canal de $\mathrm{Ca}^{2+}$, por unos segundos y posteriormente vuelve a establecerse su potencial de membrana en reposo con la apertura del canal de $\mathrm{K}_{\text {ATP }}^{+}$(Aguilar y col., 1998).

El resultado de que el extracto acuoso de C. ficifolia no bloquea los canales de

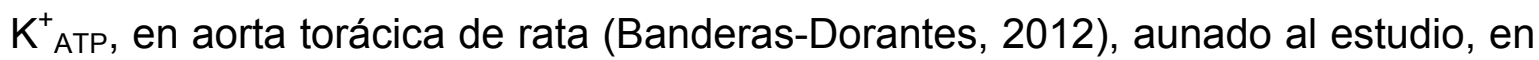
el que se observa mayor secreción de insulina en ratones tratados con este extracto (García-González, 2011), nos llevo a estudiar la actividad del extracto en 
un modelo in vitro. Confirmando su efecto en el aumento de la síntesis y secreción de insulina. Aunado al antecedente de que dos genes KIR6.x y dos genes SUR han sido identificados. Las combinaciones de subunidades dan lugar a subtipos de canales $\mathrm{K}_{\mathrm{ATP}}^{+}$que se encuentran en las células pancreáticas, neuronas, músculo cardíaco, esquelético y liso. En las células estos canales se componen de subunidades Kir6.2 que forman el canal y por una porción del canal llamada SUR1, que son codificadas por los genes KCNJ11 y ABCC8, respectivamente (Fatehi y col., 2012). Abriendo la posibilidad de que el extracto acuso de $C$. ficifolia actúe específicamente sobre el canal de $\mathrm{K}_{\text {ATP }}^{+}$de la célula y no como la glibenclamida, que ejerce su acción de manera no específica. Bloquea los canales de $\mathrm{K}_{\text {ATP }}^{+}$que se encuentran en todo el cuerpo.

El suministro de $\mathrm{Ca}^{2+}$ en la célula , induce la exocitosis de insulina mediada por segundos mensajeros dependientes de $\mathrm{Ca}^{2+}$, como la fosfolipasa C (PLC). La PLC se encarga de hidrolizar al fosfatidilinositol bifosfato $\left(\mathrm{PIP}_{2}\right)$ en diacilglicerol (DAG) e inositol trifosfato $\left(\mathrm{IP}_{3}\right)$. El DAG activa a la proteína cinasa $\mathrm{C}(\mathrm{PKC})$ que también puede activarse por $\mathrm{Ca}^{2+}$ libre del citoplasma e induce la exocitosis de la insulina. Así mismo, el $\mathrm{IP}_{3}$ entra al RE para liberar más $\mathrm{Ca}^{2+}$ al citoplasma (Henquin, 2004), (Yamazaki y col., 2010). El receptor inositol 1,4,5-trifosfato (InsP3R) es un canal de $\mathrm{Ca}^{2+}$ que se encuentra en $\mathrm{RE}$ sensible a $\mathrm{IP}_{3}$. Juega un papel en la regulación de la secreción de insulina (Lee y col., 1998).

Este estudio abre la posibilidad de nuevas preguntas de investigación. Una de ellas es, determinar si el extracto acuoso de C. ficifolia aumenta la concentración de $\mathrm{Ca}^{2+}$ mediante el receptor InsP3R o a través de la activación específica de los canales de $\mathrm{K}_{\text {ATP }}^{+}$de la célula . Se ha reportado que estos canales tetradiméricos 
están compuestos por diferentes subunidades del receptor Kirx-SURx en músculo liso vascular, que en la célula .

El extracto acuoso de I. sonorae aumenta la concentración de $\mathrm{Ca}^{2+}$ intracelular. Esto concuerda con el resultado de que el extracto acuoso de I. sonorae sí bloquea los canales de $\mathrm{K}_{\mathrm{ATP}}^{+}$, en aorta torácica de rata (Banderas-Dorantes, 2012).

La mayoría de la insulina secretada por las células es la que se encuentra en los reservorios, es decir, los gránulos de insulina preformados. Para su liberación, los gránulos deben ser reclutados hacía la membrana plasmática del citoplasma, donde son acoplados para la fusión de membranas y liberar su contenido en el espacio extracelular (Ren y col., 2007). Es probable que el extracto acuoso de $I$. sonorae sólo movilice los gránulos de insulina preformados, induciendo su secreción.

Estos datos representan una aproximación del efecto hipoglucémico, tanto del extracto acuoso de C. ficifolia, como del extracto acuoso de $I$. sonorae. Por un lado, el extracto acuoso de C. ficifolia, al parecer, activa al gen de insulina e incrementa el $\mathrm{Ca}^{2+}$ intracelular. Es probable que esté activando factores de transcripción involucrados como MAfA, PDX-1 y NeuroD-1 en la activación del gen de insulina. El aumento en la concentración de $\mathrm{Ca}^{2+}$ intracelular, proveniente de la apertura del canal de $\mathrm{K}^{+}{ }_{\text {ATP. }}$ La movilización del $\mathrm{Ca}^{2+}$ intracelular, también puede provenir de RE. Por lo que sugerimos que el mecanismo hipoglucemiante del extracto acuoso de C. ficifolia es mucho más complejo que el de glibenclamida, en las célula RINm5F. 
Por otro lado, el extracto acuoso de I. sonorae disminuye la expresión del gen de insulina de las células RINm5F, sin embargo, aumenta la concentración de $\mathrm{Ca}^{2+}$ intracelular, induciendo la secreción de los gránulos preformados que contienen a la insulina. Por lo que el mecanismo del extracto acuoso de $I$. sonorae es más parecido al mecanismo de acción de glibenclamida.

\section{CONCLUSIONES}

1. El extracto acuoso de C. ficifolia y el DQI aumentan la expresión del RNAm de insulina y de Kir6.2, incrementan el $\mathrm{Ca}^{2+}$ intracelular y la secreción de insulina.

2. El extracto acuoso de I. sonorae disminuye la expresión del gen de insulina, sin modificar la de Kir6.2, aumenta la concentración de $\mathrm{Ca}^{2+}$ intracelular e induce la secreción de insulina.

3. La acción hipoglucemiante de ambos extractos es a través de diferentes mecanismos que modulan la producción y liberación de insulina. 


\section{PERSPECTIVAS}

Cucurbita ficifolia Bouché

Se propone establecer sí los canales de KATP, la movilización de $\mathrm{Ca}^{+}{ }_{\mathrm{i}}$, y los factores de transcripción del gen de insulina (MafA, Pdx-1, NeuroD1/Beta2) participan en el mecanismo de acción hipoglucemiante de C. ficifolia y del DQI.

Ibervillea sonorae Grenne

Se propone establecer si el aumento en la secreción de insulina por I. sonorae está mediado por la apertura de canales de $\mathrm{K}^{+}{ }_{\text {ATP }}$ en la línea RINm5F. 


\section{REFERENCIAS BIBLIOGRÁFICAS}

Acosta JL, Jimenez E, Juarez MA, Diaz JC (2001) Hypoglycemic action of Cucurbita ficifolia on type 2 diabetic patients with moderately high blood glucose levels. J Ethnopharmacol. 77(1):99-101.

Aguilar-Bryan L, Clement JP 4th, Gonzalez G, Kunjilwar K, Babenko A, Bryan J. 1998, Toward understanding the assembly and structure of KATP channels. Physiol Rev. 78(1):227-245.

Aguilar-Salinas C A. 2011, La diabetes tipo 2 en México: Principales retos y posibles soluciones. Revista de la ALAD. 1(4):148-161.

Alarcón, F, Calzada F, Hernández E. 2005, Acute and chronic hypoglycemic effect of Ibervillea sonorae root extracts-II. J Ethnopharmacol. 97(3): 447-452.

Alarcon-Aguilar FJ, Hernandez-Galicia E, Campos-Sepulveda AE, XolalpaMolina S, Rivas-Vilchis JF, Vazquez-Carrillo LI, Roman-Ramos R. 2002, Evaluation of the hypoglycemic effect of Cucurbita ficifolia Bouche (Cucurbitaceae) in different experimental models. J Ethnopharmacol 82(23):185-189.

Alarcón-Aguilar F, Pérez M, Verde J, Zavala M, Jasso E, Sánchez M, Almanza J, Román R. 2008, Efecto hipoglucémico y contenido de ácidos grasos en tubérculos de Ibervillea sonorae Greene colectados a lo largo del año. Anuario de investigación en etnomedicina, pp 69-73.

Alarcón FJ, Hernandez E, Campos AE, Xolalpa S, Rivas JF, Vazquez LI, Roman R. 2002, Evaluation of the hypoglycemic effect of Cucurbita ficifolia Bouché (Cucurbitaceae) in different experimental models. 2012, J Ethnopharmacol. 82(2-3):185-189. 
American Diabetes Association, 2011, Standards of medical care in diabetes. Diabetes Care. 34 Suppl 1:S11-61.

Andrade-Cetto A, Heinrich M. 2005, Mexican plants with hypoglycaemic effect used in the treatment of diabetes. J Ethnopharmacol. 99(3):325-348.

Baci Y, Ustüner I, Keskin HL, Ersoy R, Av ar AF. 2012, Effect of maternal obesity and weight gain on gestational diabetes mellitus. Gynecol Endocrinol. doi:10.3109/09513590.2012.730571.

Banderas-Dorantes T, Roman RR, Zamilpa A, García MR, Díaz M. Campos MG, Tortoriello J, Alarcón FJ. 2012, Influence of two hypoglycemic Cucurbitaceae (Cucurbita ficifolia Bouché and Ibervillea sonorae Greene) on ATP-sensitive potassium channels in rat thoracic. BLACPMA (en prensa).

Barbarroja N, Lopez-Pedrera C, Garrido-Sanchez L, Mayas MD, Oliva-Olivera W, Bernal-Lopez MR, El Bekay R, Tinahones FJ. 2012, Progression from high insulin resistance to type 2 diabetes does not entail additional visceral adipose tissue inflammation. PLoS One. 7(10):e48155.

Bartolome A, Guillen C, Benito M. 2012, Autophagy plays a protective role in endoplasmic reticulum stress-mediated pancreatic cell death. Autophagy. 8(12):1-12.

Bellomo G, Jewell S, Thor J, Orreniust S. 1982, Regulation of intracellular calcium compartmentation: Studies with isolated hepatocytes and t-butyl hydroperoxide. Proc. Nati Acad. 79(22):6842-6846.

Börgeson E, Godson C. 2012, Resolution of inflammation: therapeutic potential of pro-resolving lipids in type 2 diabetes mellitus and associated renal complications. Front Immunol. doi: 10.3389/fimmu.2012.00318. 
Bradan M, Laher I. 2012, Type II Diabetes Mellitus in Arabic-Speaking Countries. Endocrinology. doi: 10.1155/2012/902873.

Brunetti A, Chiefari E, Foti D. 2011, Perspectives on the contribution of genetics to the pathogenesis of type 2 diabetes mellitus. Recenti Prog Med. 102(12):468-475.

Cerra M, Luo WL, Li SX, Matthews C, O'Neill EA, Wagner JA, Stoch SA, Anderson MS. 2012, The effects of simvastatin on the pharmacokinectics of sitagliptin. J Popul Ther Clin Pharmacol. 19(3):356-360.

Chaithongdi N, Subauste JS, Koch CA, Geraci SA. 2011, Diagnosis and management of hyperglycemic emergencies. Hormones (Athens). 10(4):25060 .

Cho IS, Jung M, Kwon KS, Moon E, Cho JH, Yoon KH, Kim JW, Lee YD, Kim SS, Suh-Kim H. 2012, Deregulation of CREB signaling pathway induced by chronic hyperglycemia downregulates NeuroD transcription. PLoS One. 7(4):115.

Choi K, Kim Y. 2010, Molecular mechanism of insulin resistence in obesity and type 2 diabetes. Endocrinology. 25(2):119-129.

Chomczynski P.A. 1993, Reagent for the single step simultaneous isolation of RNA, DNA and proteins from cells and tissue samples, Biotechiques 15(3):532-4, 536-7.

Contreras-Weber C, Perez-Gutierrez S, Alarcon-Aguilar F, Roman-Ramos R. 2002, Anti-hyperglycemic effect of Psacalium peltatum. Proc West Pharmacol Soc. 45:134-6. 
De Cosmo S, Menzaghi C, Prudente S, Trischitta V. 2012, Role of insulin resistance in kidney dysfunction: insights into the mechanism and epidemiological evidence. Nephrol Dial Transplant. doi: 10.1093/ndt/gfs290.

D'Elia JA, Bayliss G, Roshan B, Maski M, Gleason RE, Weinrauch LA. 2011, Diabetic microvascular complications: possible targets for improved macrovascular outcomes. Int $\mathrm{J}$ Nephrol Renovascular Dis. doi: 10.2147/IJNRD.S14716.

DGE. 2009. Dirección General de Epidemiología. www.dgepi.salud.gob.mx (Fecha de consulta: 18/Febrero/2009).

Eckel RH, Kahn SE, Ferrannini E, Goldfine AB, Nathan DM, Schwartz MW, Smith RJ, Smith SR. 2011, Obesity and Type 2 Diabetes: What Can Be Unified and What Needs to Be Individualized? Diabetes Care. 34(6): 1424-1430.

Escobedo-de la Peña J, Buitrón-Granados LV, Ramírez-Martínez JC, ChaviraMejía R, Schargrodsky H, Champagne BM. 2011, Diabetes in Mexico. CARMELA study. Cir Cir. 79(5):424-431.

Fatehi M, Raja M, Carter C, Soliman D, Holt A, Light PE. 2012, The ATPsensitive $\mathrm{K}(+)$ channel $A B C C 8$ S1369A type 2 diabetes risk variant increases MgATPase activity. Diabetes. 61(1):241-249.

Farnsworth NR, Marles RJ. 1995, Antidiabetic plants and their active constituents. Phytomedicine 2:137-189.

Fernandez-Valverde SL, Taft RJ, Mattick JS. 2011, MicroRNAs in -cell biology, insulin resistance, diabetes and its complications. Diabetes. 60(7):1825-1831. 
Ferreira Hermosillo A, Vargas Ortega G, González Virla B, Mercado Atri M, Molina Ayala M. 2012, Prevalence of metabolic syndrome (MS) in patients with type 1 diabetes (DM1). Gac Med Mex. 148(2):137-143.

Figuerola D. 1997, Diabetes. Tercera edición. Ed. Masson, S.A. Madrid, España. pp. 19-25.

Florez Jesús, Armijo Juan Antonio, MediaVilla África. 1997, Farmacología Humana, 3ra Edición, Ed. Masson, Capítulo 54. S. A, México. pp 927- 943.

FMD. Federación Mexicana de Diabetes. www.fmdiabetes.com. (Fecha de consulta: 18/Febrero/2009).

Fu LL, Lin Y, Yang ZL, Yin YB. 2012, Association analysis of genetic polymorphisms of TCF7L2, CDKAL1, SLC30A8, HHEX genes and microvascular complications of type 2 diabetes mellitus. Zhonghua. 29(2):194199.

Gaddam K, Ventura H, Lavie C. 2011, Metabolic Syndrome and heart failurethe risk, paradox and treatment. Curr Hypertens Rep 13(2):142-148.

Gagliardino J. Physiological endocrine control of energy homeostasis and postprandial blood glucose levels. 2005, European Review for Medical and Pharmacological Sciences 9(2):75-92.

Gamboa-Meléndez MA, Huerta-Chagoya A, Moreno-Macías H, VázquezCárdenas $P$, Ordóñez-Sánchez ML, Rodríguez-Guillén R, Riba L, RodríguezTorres M, Guerra-García MT, Guillén-Pineda LE, Choudhry S, Del BosquePlata L, Canizales-Quinteros S, Pérez-Ortiz G, Escobedo-Aguirre F, Parra A, Lerman-Garber I, Aguilar-Salinas CA, Tusié-Luna MT. 2012, Contribution of 
Common Genetic Variation to the Risk of Type 2 Diabetes in the Mexican Mestizo Population. Diabetes. doi: 10.2337/db11-0550.

Gao N, White P, Doliba N, Golson ML, Matschinsky FM, Kaestner KH. 2007, Foxa2 Controls Vesicle Docking and Insulin Secretion in Mature b Cells. Cell Metabolism. 6(4):267-279.

García-Gonzalez Jessica. 2009, Daños histológicos en varios órganos de ratón, por el efecto de varias plantas antidiabéticas. Licenciatura en Biología Experimental, UAM-Iztapalapa.

García-González Jessica. 2011, Proliferación de células pancreáticas en ratones diabéticos tratados con Cucurbita ficifolia Bouché. Maestría en Biología Experimental, UAM-Iztapalapa.

Gardner TW, Abcouwer SF, Barber AJ, Jackson GR. 2012, An Integrated Approach to Diabetic Retinopathy Research. Arch Ophthalmol. 129(2):230235.

Ghiselli A, Nardini M, Baldi A, Scaccini C. 1998, Antioxidant Activity of Different Phenolic Fractions Separated from an Italian Red Wine. J Agric Food Chem. 46(2):361-367.

Giuliani L, Mele R, Giovine MD, Altieri L, Crinò A, Ravà L, Fierabracci A. 2009, Detection of GAD65 Autoreactive T-Cells by HLA Class I Tetramers in Type 1 Diabetic Patients. J Biomed Biotechnol. doi: 10.1155/2009/576219.

Hernández-Galicia E, Calzada F, Roman-Ramos R, Alarcón-Aguilar FJ. 2007, Monoglycerides and fatty acids from Ibervillea sonorae root: isolation and hypoglycemic activity. Planta Med. 73(3):236-240.

Henquin JC. 2004, Pathways in -Cell Stimulus-Secretion Coupling as Targets for Therapeutic Insulin Secretagogues. Diabetes. 53 Suppl 3:S48-58. 
H M, Górecka D, Dziedzic K. 2012, Antioxidant properties of extracts from buckwheat by-products. Acta Sci Pol Technol Aliment. 11(2):167-174.

Hoimark L, Laursen T, Rungby J. 2012, Potential role of linagliptin as an oral once-daily treatment for patients with type 2 diabetes. Diabetes Metab Syndr Obes. doi: 10.2147/DMSO.S16288.

Inada A, Someya Y, Yamada Y, Ihara Y, Kubota A, Ban N, Watanabe R, Tsuda K, Seino Y. 1999, The cyclic AMP response element modulator family regulates the insulin gene transcription by interacting with transcription factor IID. J Biol Chem. 274(30):21095-21103.

Itoh Y, Kawamata Y, Harada M, Kobayashi M, Fujii R, Fukusumi S, Ogi K, Hosoya M, Tanaka Y, Uejima H, Tanaka H, Maruyama M, Satoh R, Okubo S, Kizawa H, Komatsu H, Matsumura F, Noguchi Y, Shinohara T, Hinuma S, Fujisawa Y, Fujino M. 2003, Free fatty acids regulatated insulina secretion from pancreatic -cells through GPR40. Nature. 422(6928):173-176.

Ishiguro N, Shimizu H, Kishimoto W, Ebner T, Schaefer O. 2012, Evaluation and Prediction of Potential Drug-drug Interactions of Linagliptin using In Vitro Cell Culture Methods. Drug Metab Dispos. doi: 10.1124/dmd.112.048470.

Juhl C, Grøfte T, Butler PC, Veldhuis JD, Schmitz O, Pørksen N. 2002, Effects of Fasting on Physiologically Pulsatile Insulin Release in Healthy Humans. Diabetes 51 Suppl 1:S255-257.

Kaneto H, Sharma A, Suzuma K, Laybutt DR, Xu G, Bonner-Weir S, Weir GC. 2002, Induction of c-Myc expression suppresses insulin gene transcription by inhibiting NeuroD/BETA2-mediated transcriptional activation. J Biol Chem. 277(15):12998-3006. 
Kerkeni M, Saïdi A, Bouzidi H, Letaief A, Ben Yahia S, Hammami M. 2102, Pentosidine as a biomarker for microvascular complications in type 2 diabetic patients. Diab Vasc Dis Res. doi: 10.1177/1479164112460253.

Ketterer C, Müssig K, Machicao F, Stefan N, Fritsche A, Häring HU, Staiger H. 2011, Genetic variation within the NR1H2 gene encoding liver $X$ receptor associates with insulin secretion in subjects at increased risk for type 2 diabetes. J Mol Med (Berl). 89(1):75-81.

Khan AR, Awan FR. 2012, Review: Mining of protein based biomarkers for type 2 diabetes mellitus. Pak J Pharm Sci. 25(4):889-901.

Kirkpatrick CL, Wiederkehr A, Baquié M, Akhmedov D, Wang H, Gauthier BR, Akerman I, Ishihara H, Ferrer J, Wollheim CB. 2011, Hepatic Nuclear Factor 1 alpha\} (HNF1 \{alpha\}) Dysfunction Down-regulates X-box-binding Protein 1 (XBP1) and Sensitizes \{beta\}-Cells to Endoplasmic Reticulum Stress. J Biol Chem. 286(37):32300-32312.

Krentz AJ, Bailey CJ. 2012, Oral antidiabetic agents: current role in type 2 diabetes mellitus. Drugs. 65(3):385-411.

Lammoglia J J, Hernández M I, Ananue N, Román R, Villanueva J, Ávila A, Mericq V, Codner E, Cassorla F. 2008, Insulinoma, presentación y evolución de dos casos clínicos. Rev Chil Pediatr. 79(2):181-185.

Lantz KA, Vatamaniuk MZ, Brestelli JE, Friedman JR, Matschinsky FM, Kaestner KH. 2004, Foxa2 regulates multiple pathways of insulin secretion. J. Clin. Invest. 114(4):512-520. 
Larner J. 2001, D-Chiro-Inositol in Insulin Action and Insulin Resistance-OldFashioned Biochemistry Still at Work. IUBMB Life. 51(3):139-148.

Lee B, Bradford PG, Laychock SG 1998 Characterization of inositol 1,4,5trisphosphate receptor isoform mRNA expression and regulation in rat pancreatic islets, RINm5F cells and betaHC9 cells. J Mol Endocrinol. 21(1):3139.

Lee JK, Cho JH, Hwang WS, Lee YD, Reu DS, Suh-Kim H. 2000, Expression of neuroD/BETA2 in mitotic and postmitotic neuronal cells during the development of nervous system. Dev Dyn. 217(4):361-367.

Lu M, Seufert J, Habener JF. 1997, Pancreatic beta-cell-specific repression of insulin gene transcription by CCAAT/enhancer-binding protein beta. Inhibitory interactions with basic helix-loop-helix transcription factor E47. J Biol Chem. 272(45):28349-28359.

Manoel-Caetano FS, Xavier DJ, Evangelista AF, Takahashi P, Collares CV, Puthier D, Foss-Freitas MC, Foss MC, Donadi EA, Passos GA, Sakamoto-Hojo ET. 2012, Gene expression profiles displayed by peripheral blood mononuclear cells from patients with type 2 diabetes mellitus focusing on biological processes implicated on the pathogenesis of the disease. Gene. 511(2):151160.

Marchetti P, Lupi R, Del Guerra S, Bugliani M, Marselli L, Boggi U. 2010, The - Cell in human Type 2 Diabetes. Capítulo 22. The Islets of Langerhans, advances in experimental medicine and biology. Ed. M. S. Islam. Pisa Italy. pp 501-511. 
Marsich E, Vetere A, Di Piazza M, Tell G, Paoletti S. 2003, The PAX6 gene is activated by the basic helix-loop-helix transcription factor NeuroD/BETA2. Biochem J. 376(Pt 3):707-715.

Martin-Gronert MS, Ozanne SE. 2012, Metabolic programming of insulin action and secretion. Diabetes Obes Metab. 14 Suppl 3:29-39.

Matsuda T, Ferreri K, Todorov I, Kuroda Y, Smith CV, Kandeel F, Mullen Y. 2005, Silymarin protects pancreatic beta-cells against cytokine-mediated toxicity: implication of c-Jun $\mathrm{NH}$-terminal kinase and janus kinase/signal transducer and activator of transcription pathways. Endocrinology. 146(1):175185.

Meyer MR, Clegg DJ, Prossnitz ER, Barton M. 2011, Obesity, Insulin Resistance and Diabetes: Sex Differences and Role of Estrogen Receptors. Acta Physiol (Oxf). 203(1):259-269.

Montanya Mias E, Téllez Besolí N. 2007, Control y Mecanismos Implicados en la Secreción de Insulina. En: Tratado SED de Diabetes Mellitus. Bases moleculares, clínica y tratamiento. Madrid, España. Editorial Médica Panamericana (Ed) P:111-122.

Mosmann T. 1983, Rapid colorimetric assay for cellular growth and survival: Application to proliferation and cytotoxicity assay. J. Inmunol. Methods 1983. 65(1-2):55-63.

Musabayane CT. 2012, The effects of medicinal plants on renal function and blood pressure in diabetes mellitus. Cardiovasc J Afr. 23(8):462-468. 
Naka KK, Papathanassiou K, Bechlioulis A, Kazakos N, Pappas K, Tigas S, Makriyiannis D, Tsatsoulis A, Michalis LK. 2012, Determinants of vascular function in patients with type 2 diabetes. Cardiovasc Diabetol. 11(1):127.

Naka KK, Papathanassiou K, Bechlioulis A, Pappas K, Kazakos N, Kanioglou C, Kostoula A, Vezyraki P, Makriyiannis D, Tsatsoulis A, Michalis LK. 2012, Effects of pioglitazone and metformin on vascular endothelial function in patients with type 2 diabetes treated with sulfonylureas. Diab Vasc Dis Res. $9(1): 52-58$.

Nguyen KH, Lee JH, Nyomba BL. 2011, Ethanol causes endoplasmic reticulum estress and impairment of insulin secretion in pancreatic -cells. Alcohol. 46(1):89-99.

Notkins, Abner Louis. 2002, Immunologic and Genetic Factors in Type 1 Diabetes. The Journal of Biological Chemitry. 277(46):43545-43548.

Olokoba AB, Obateru OA, Olokoba LB. 2012, Type 2 diabetes mellitus: a review of current trends. Oman Med J. 27(4):269-273.

OMS. World Health organization Department of Noncommunicable Disease Surveillance, "Diagnosis and classification of diabetes mellitus and its complications," WHO. 1999, http:// whqlibdoc.who.int/hq/1999/WHO NCD NCS 99.2.pdf.

Palgi J, Stumpf E, Otonkoski T. 2000, Transcription factor expression and hormone production in pancreatic AR42J cells. Mol Cell Endocrinol. 165(12):41-49. 
Pedret A, Valls RM, Fernández-Castillejo $S$, Catalán U, Romeu M, Giralt $M$, Lamuela-Raventós RM, Medina-Remón A, Arija V, Aranda N, Espinel A, Delgado MA, Solà R. 2012, Polyphenol-rich foods exhibit DNA antioxidative properties and protect the glutathione system in healthy subjects. Mol Nutr Food Res. 56(7):1025-1033.

Piro S, Anello M, Di Pietro C, Lizzio MN, Patanè G, Rabuazzo AM, Vigneri R, Purrello M, Purrello F. 2002, Chronic exposure to free fatty acids or high glucose induces apoptosis in rat pancreatic islets: possible role of oxidative stress.51(10):1340-1347.

Poy MN, Eliasson L, Krutzfeldt J, Satoru Kuwajima, Xiaosong Ma, Patrick E. MacDonald, Sébastien Pfeffer, Thomas Tuschl, Nikolaus Rajewsky, Patrik Rorsman Markus Stoffel. 2004, A pancreatic islet-specific microRNA regulates insulin secretion. Nature. 432:226-230.

Povel CM, Beulens JW, van der Schouw YT, Dollé ME, Spijkerman AM, Verschuren WM, Feskens EJ, Boer JM. 2012, Metabolic Syndrome Model Definitions Predicting Type 2 Diabetes and Cardiovascular Disease. Diabetes Care. doi: 10.2337/dc11-2546.

Proks P, Reimann F, Green N, Gribble F, Ashcroft F. 2002, Sulfonylurea stimulation of insulin secretion. Diabetes 51 (Suppl. 3):S368_S376.

Ren J, Jin P, Wang E, Liu E, Harlan D M, Li X, Stroncek D F. 2007, Pancreatic islet cell therapy for type I diabetes: understanding the effects of glucose stimulation on islets in order to produce better islets for transplantation. $J$ Transl Med. doi: 10.1186/1479-5876-5-1.

Reyes OJ, Arellano PA. 2008, bases moleculares de las acciones de la insulina. Revista de Educación Bioquímica. 27(1):9-18. 
Romero Cerecero Ofelia, Reyes Morales Hortensia, Aguilar Santamaría Lucía, Huerta Reyes Maira, Tortoriello Garcia Jaime. 2009, Use of medicinal plants among patients with diabetes mellitus type 2 in Morelos, Mexico BLACPMA. 8(5):380-388.

Roman-Ramos R, Almanza-Perez JC, Fortis-Barrera A, Angeles-Mejia S, Banderas-Dorantes TR, Zamilpa-Alvarez A, Diaz-Flores M, Jasso I, BlancasFlores G, Gomez J, Alarcon-Aguilar FJ. 2012, Antioxidant and antiinflammatory effects of a hypoglycemic fraction from Cucurbita ficifolia Bouche in streptozotocin-induced diabetes mice. Am J Chin Med. 40(1):97-110.

Rorsman P, Braun M. 2012, Regulation of insulin secretion in human pancreatic islets. doi:10.1146/annurev-physiol-030212-183754.

Russell-Jones D, Gough S. 2012, Recent advances in incretin-based therapies. Clin Endocrinol (Oxf). 77(4):489-499.

Schuit F, Van Lommel L, Granvik M, Goyvaerts L, de Faudeur G, Schraenen A, Lemaire K. 2012, -cell-specific gene repression: a mechanism to protect against inappropriate or maladjusted insulin secretion? Diabetes. 61(5):969975.

Stockert JC, Blázquez-Castro A, Cañete M, Horobin RW, Villanueva A. 2012, MTT assay for cell viability: Intracellular localization of the formazan product is in lipid droplets. Acta Histochem. 114(8):785-796.

Tiedge M, Hohne M, Lenzen S. 1993, Insulin secretion, insulin content and glucose phosphorylation in RINm5F insulinoma cells after transfection with human GLUT2 glucose-transporter cDNA. Biochem. J. 296(Pt1):113-118.

Triplitt CL. 2012, Examining the mechanisms of glucose regulation. Am J Manag Care. 18(1 Suppl):S4-10. 
Wang Xin, Zhang A, Liu Y, Chen S, Feng Z, Shang W, Maziarz M, Radtke J, Hampe CS. 2012, Anti-Idiotypic Antibody Specific to GAD65 Autoantibody Prevents Type 1 Diabetes in the NOD Mouse. PLoS One. doi: 10.1371/journal.pone.0032515.

Wang YH, Wu HH, Ding H, Li Y, Wang ZH, Li F, Zhang JP. 2012, Changes of insulin resistance and -cell function in women with gestational diabetes mellitus and normal pregnant women during mid- and late pregnant period: $\mathrm{A}$ case-control study. J Obstet Gynaecol Res. doi: 10.1111/j.14470756.2012.02009.x.

Wei F, Tomizawa K. 2011, Functional loss of Cdkal1, a novel tRNA modification enzyme, causes the development of type 2 diabetes. Endocr $\mathrm{J}$. 121(9):3598-3608.

Willenborg M, Hatlapatka K, Ghaly H, Belz M, Panten U, Rustenbeck I. 2011, Studies of first phase insulin secretion using imposed plasma membrane depolarization. Front Biosci (Schol Ed). 1(3):662-679.

Xia T, Wang Q. 2006, D-chiro-inositol found in Cucurbita ficifolia (Cucurbitaceae) fruit extracts plays the hypoglycaemic role in streptozocin-diabetic rats. J Pharm Pharmacol. 58(11):1527-1532.

Yamazaki H, Zawalich K, Zawalich W. 2010, Physiologic Implications of Phosphoinositides and Phospholipase $C$ in the Regulation of Insulin Secretion. $J$ Nutr Sci Vitaminol. 56(1):1-8.

Yang Y, Chang B H, Samson S L, Li M V. 2009, The Kru“ ppel-like zinc finger protein Glis3 directly and indirectly activates insulin gene transcription and Lawrence Chan. 37(8):2529-2538. 